\title{
Integration and Pedagogical Efficacy of Digital Field Methodologies in a Full-Year Sed/Strat and Structure Course
}

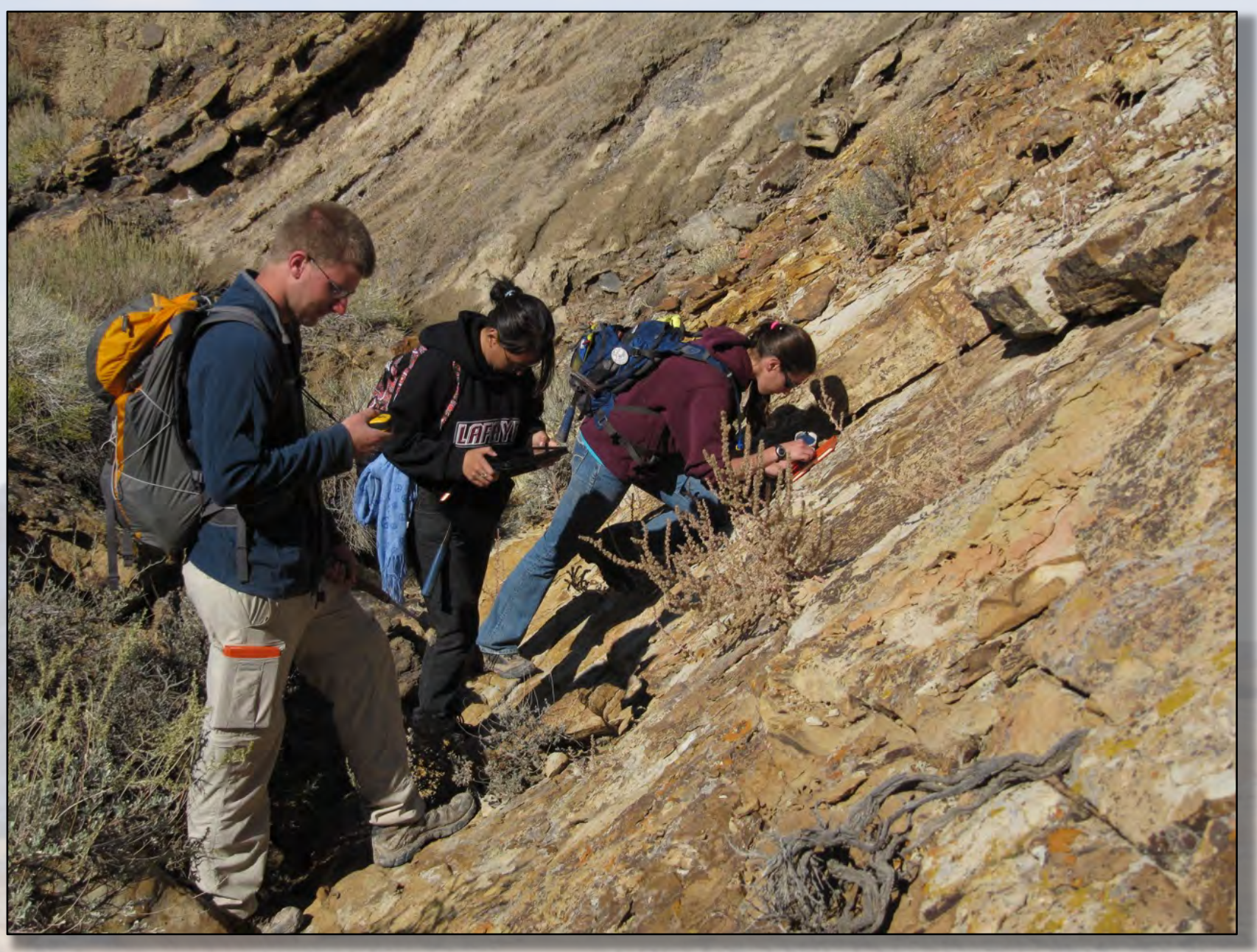

Lawrence L. Malinconico and David Sunderlin Geology \& Environmental Geosciences, Lafayette College malincol@lafayette.edu, 610-330-5195

GSA Rocky Mountain Section Meeting, June, 2017 


\section{What and Why}

- How many of you drove part... or all of the way here?

- How many used your vehicle's onboard or phone navigation App?

- When was the last time (if ever) that you use paper maps to navigate while driving?

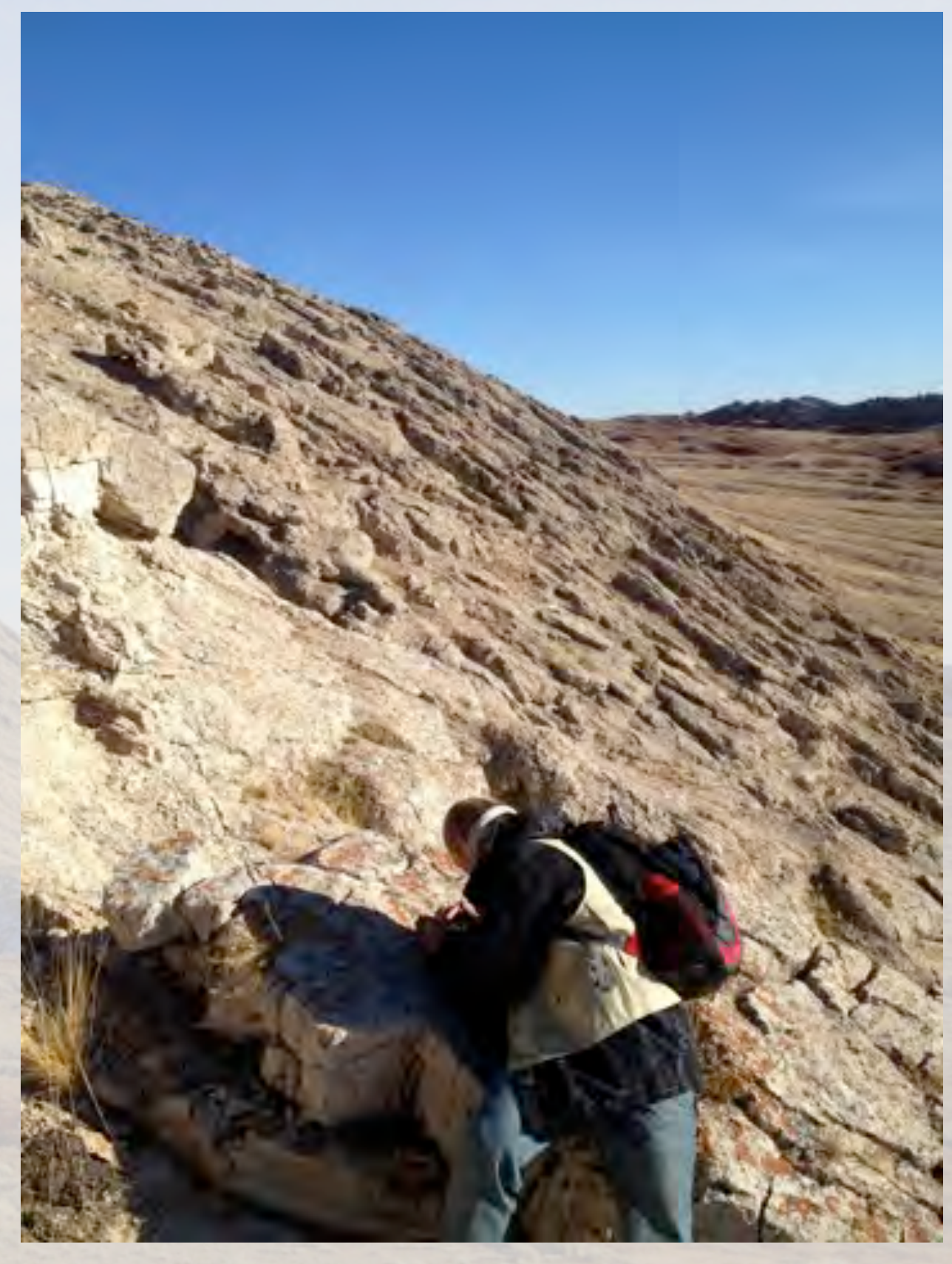




\section{Here We Go...}

- Our Geology Educational Setting (somewhat unique)

- Curricular Initiative

- Issues

- Digital Solutions

- Preliminary Assessment

- Field Issues
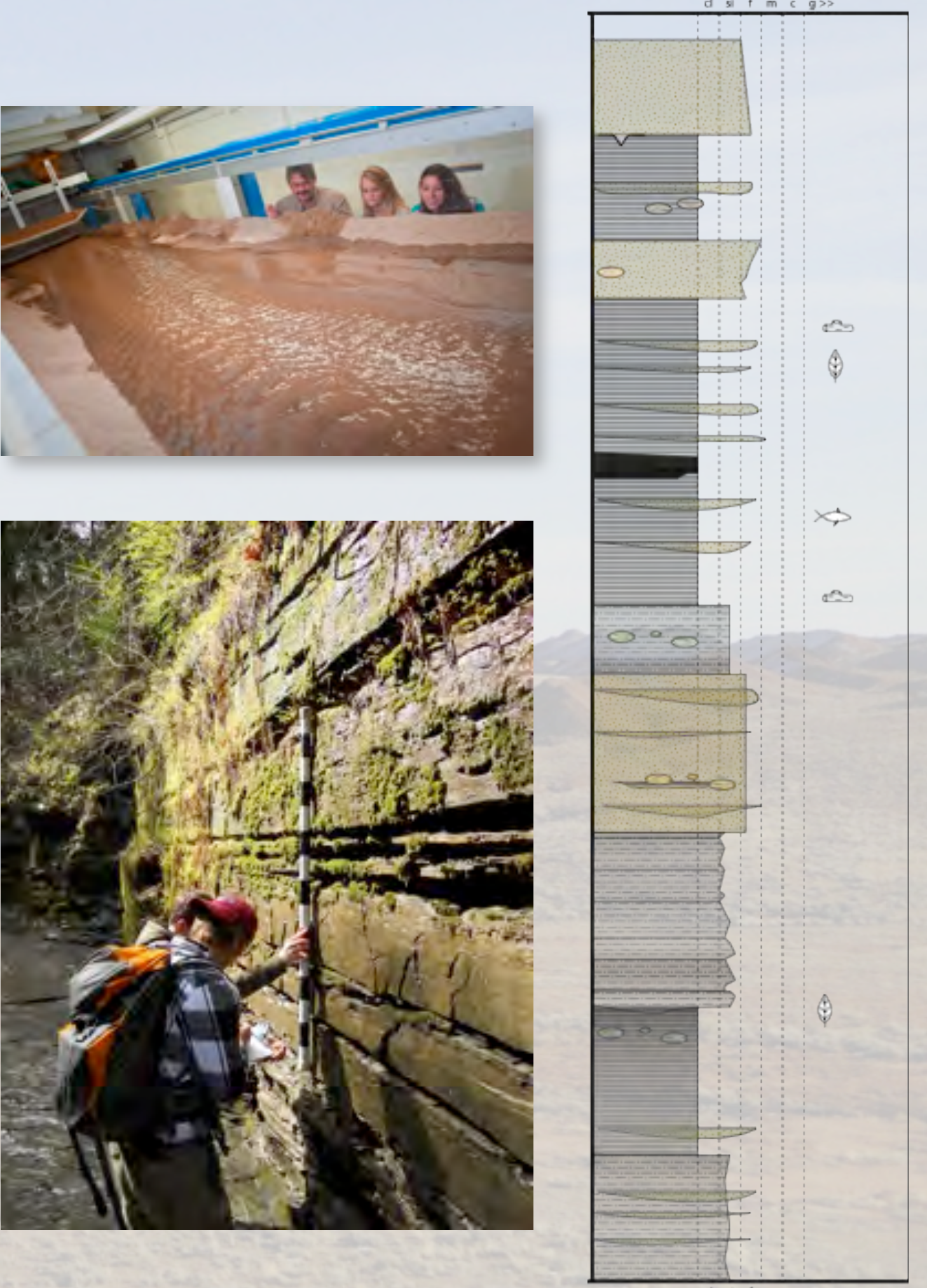


\section{Lafayette College}

- Undergraduate

- Highly selective

- 2500 students

- 8 to 15 geology graduates/year

- No field camp requirement

- Substitute: field/laboratory projects in all courses
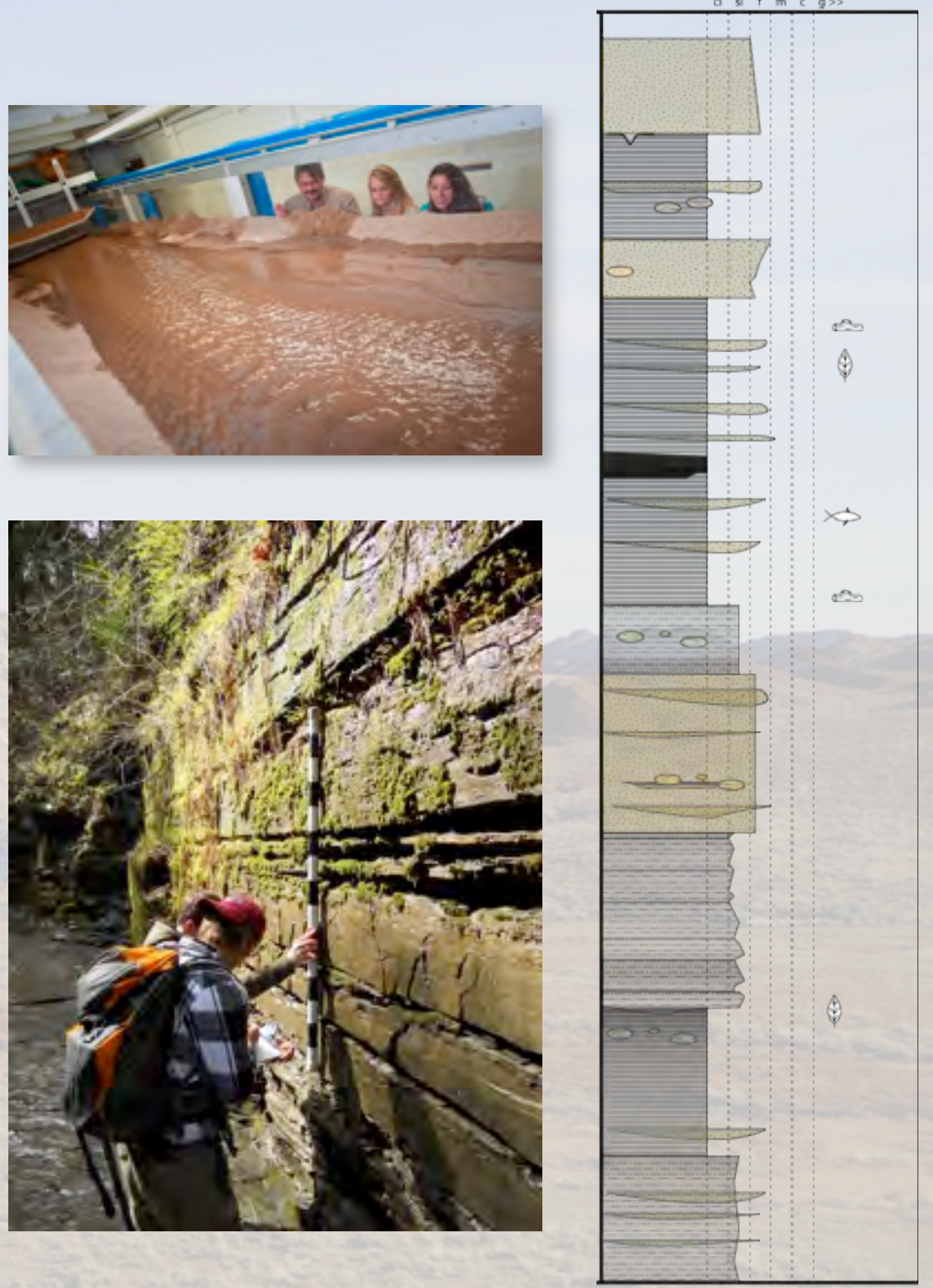


\section{Holistic Approach}

\section{Depositional \&}

Deformational Analysis

- Combined Sed/Strat \& Structural Geology into full-year sequence

- 8 to 20 students per year

- Why?

- Nothing happens in isolation (think accretionary wedges)

- How? (curricularly)

- Focus on Basin Evolution

- How? (logistically)

- share course time: 3 weeks each

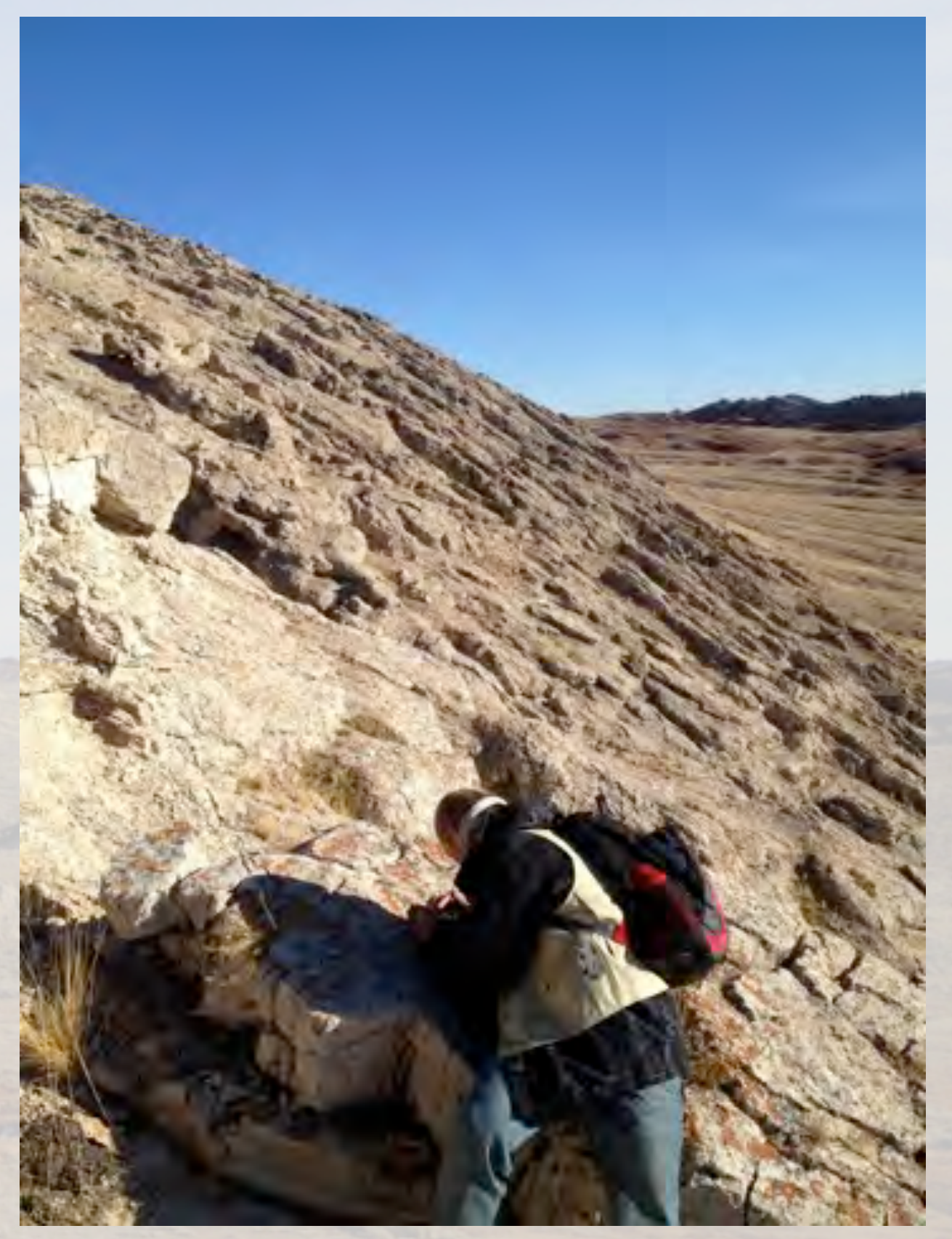
semester) 


\section{Semester 1 (GEOL 215)}

Deposition

- Topics:

- Sediment genesis -- fluid dynamics -trans/erosion/dep -- processes \& products of dep environments

- tectonics

- orogenesis/basin genesis/types

- correlation/dating

- Skillsets:

- Grain/deposit description -microscopy/sed pet -- rock ID -- field description/data collection/ interpretation -- literature research

- Products:

- Field reports of $\sim 6-8$ local units w/ lit research -- geologic history
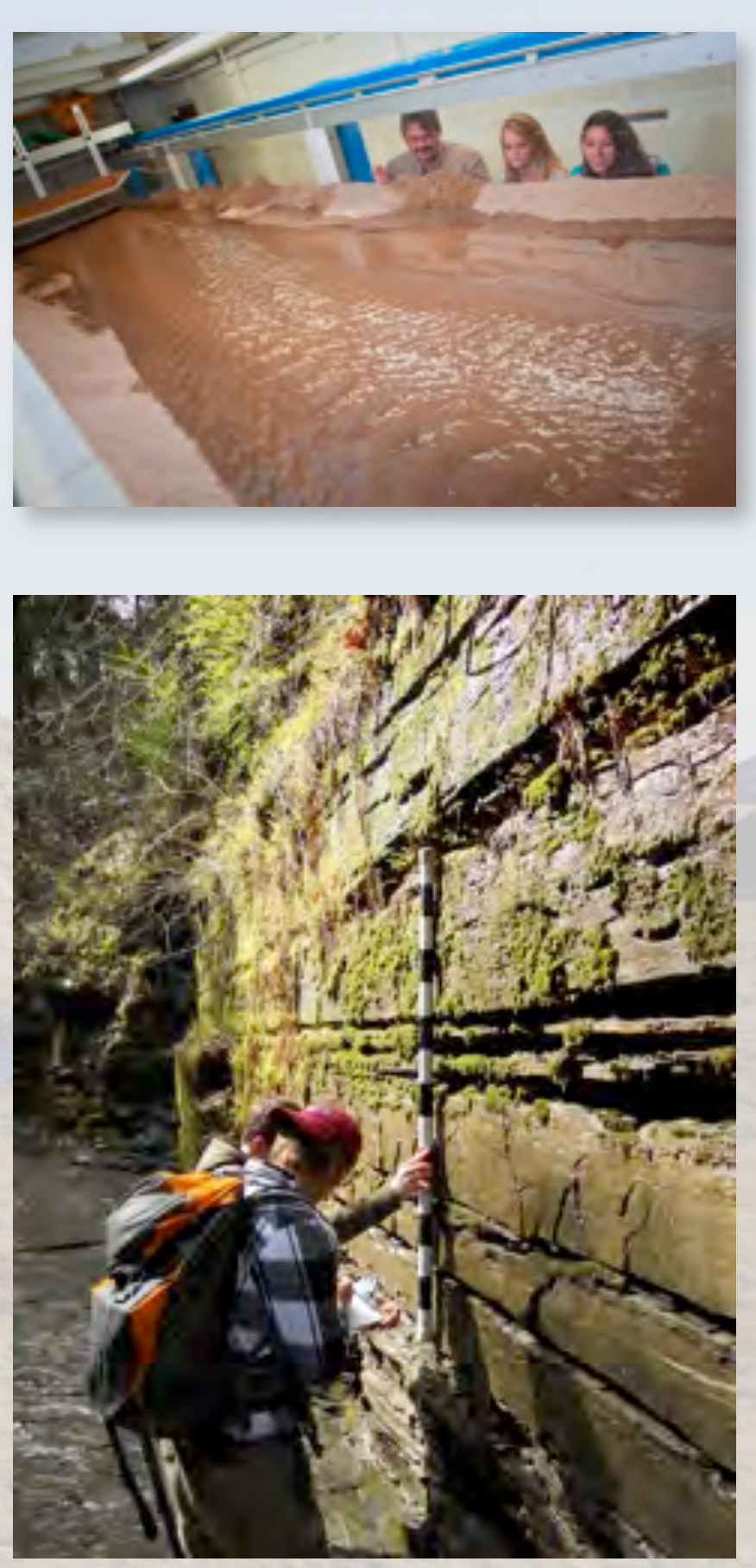

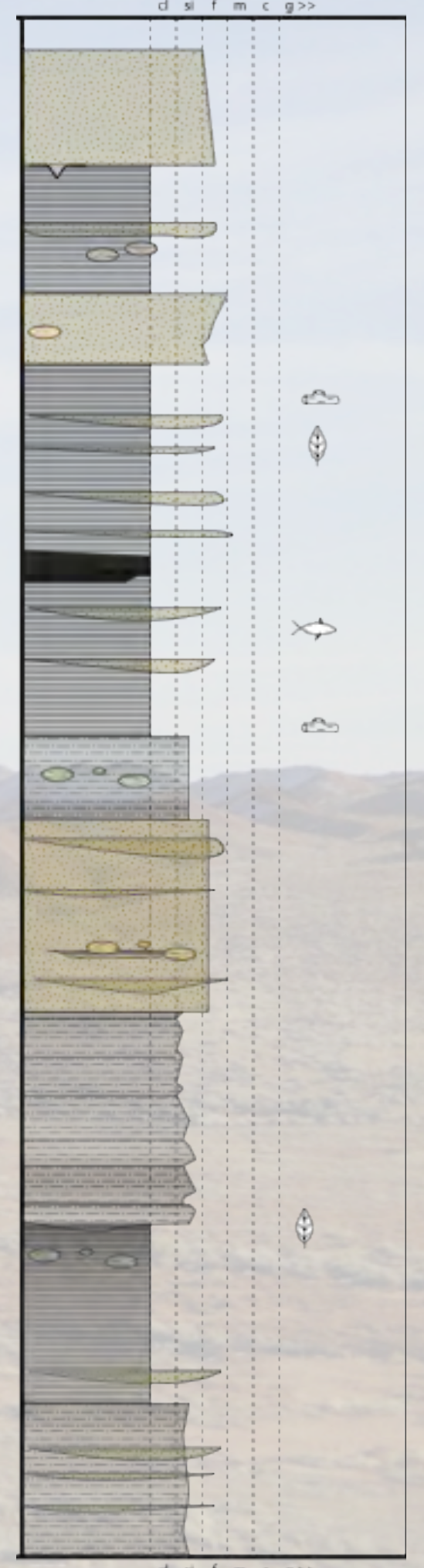




\section{Semester 2 (GEOL 317) Deformation}

- Topics:

- Relationships between Global Tectonics, mountain belts and basins -- sequence stratigraphy, petroleum generation -- stress \& strain -- brittle vs ductile -superimposed structures -- cycles of deposition and deformation

\section{- Skillsets:}

- structural field skills -- interpreting/constructing geologic maps

- ability to qualitatively and quantitatively evaluate structural features

\section{- Products:}

- synthesized into a comprehensive report:

- Regional $\rightarrow$ local relationships

- Depositional/Deformation sequences

- Strat columns -- stereoplots -- geologic maps -- crosssections



\section{Capstone: \\ Field Project/Report}

- Location: Bighorn Basin Wyoming

- Tectonics, Stratigraphy \& Structure similar to PA, except for "green" stuff
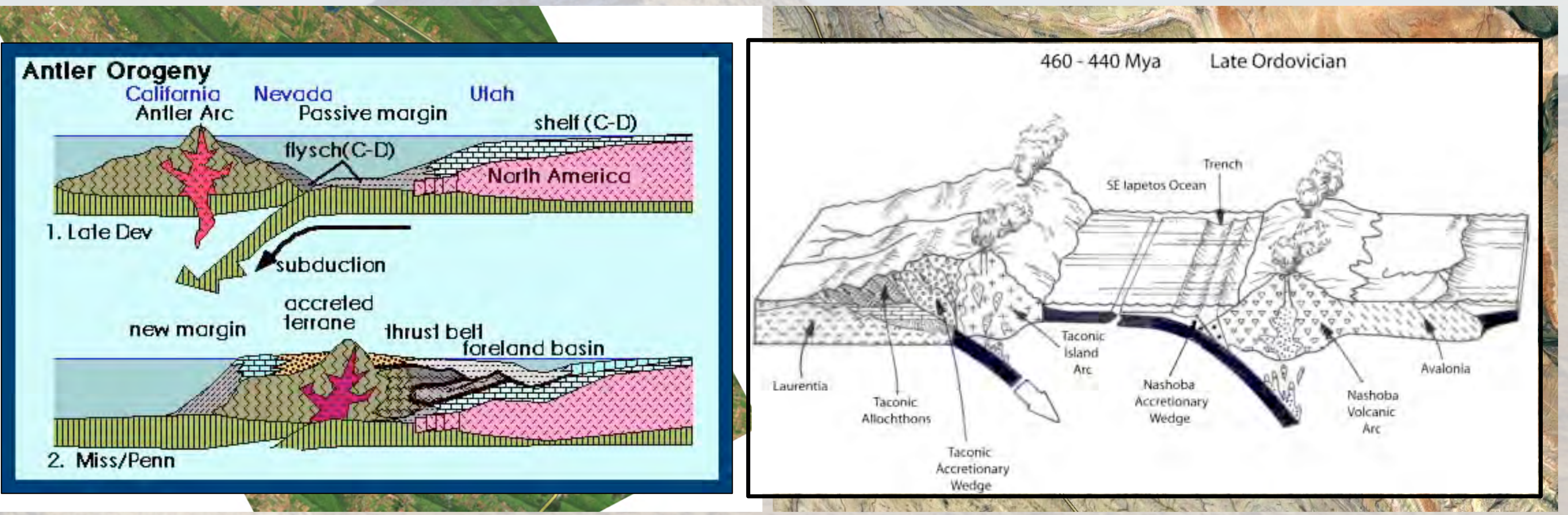


\section{Field Project}

- Plan: 5 field days -- $2.25 \mathrm{mi}^{2}$, student driven field plans

- After 16 field projects in the previous 20 weeks
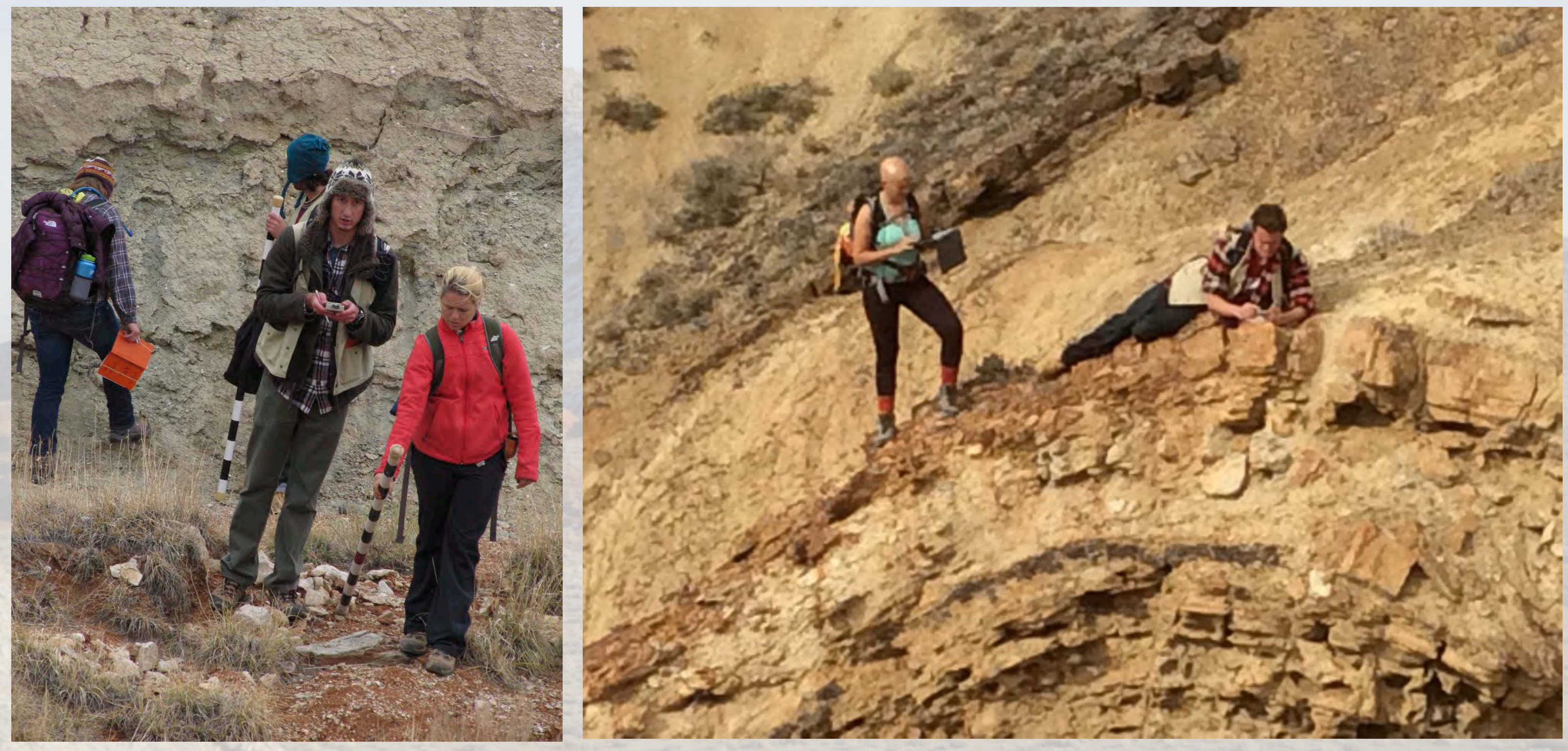


\section{The Ultimate Product}
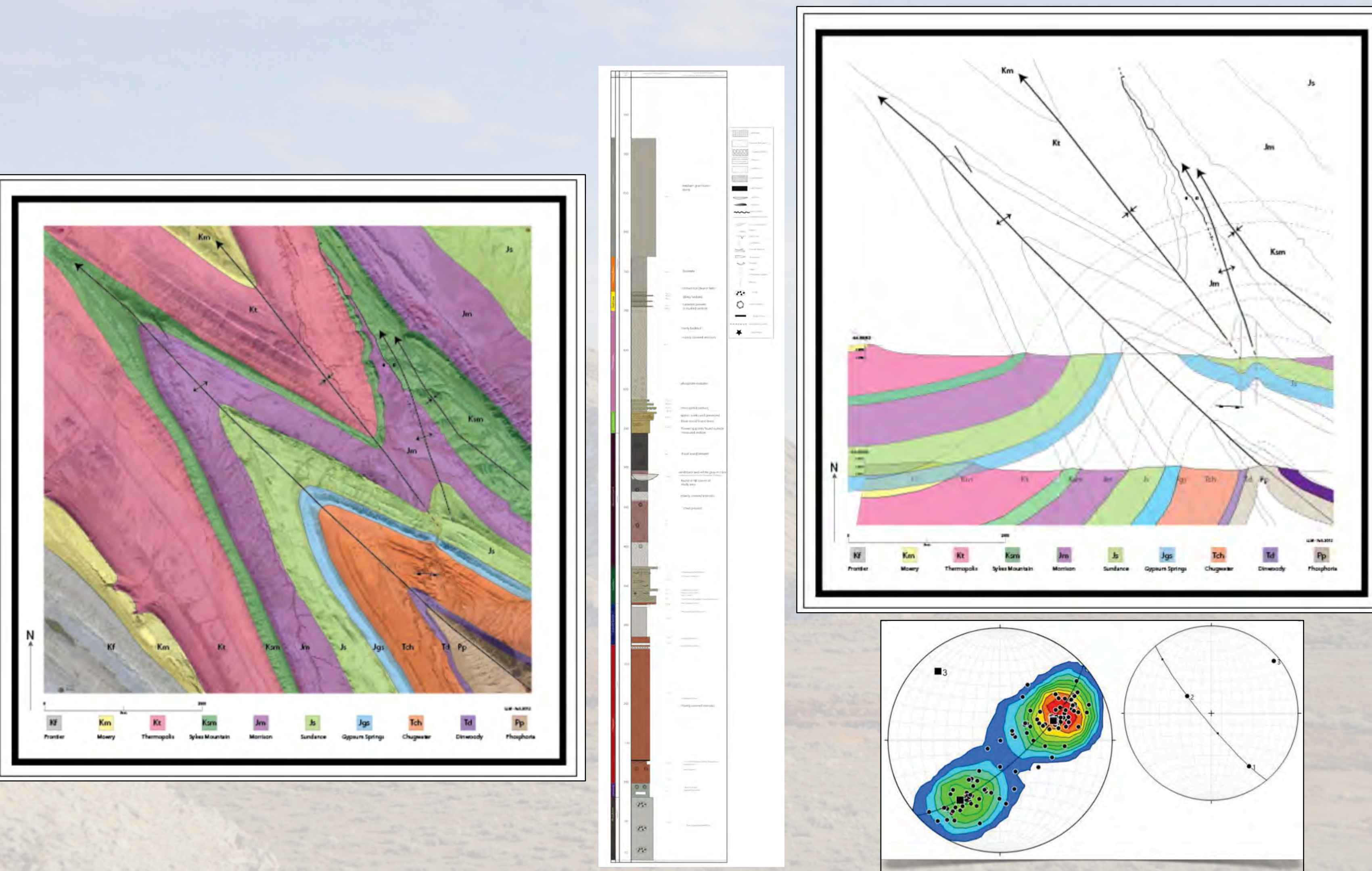


\section{The Ultimate Product}

80 to 120 page report:

- Geologic map

- Cross-section

- Strat column

- Steroeplots

- Sequence stratigraphy analysis

- Local and regional stress

- Regional tectonic history

- Antler through Laramide

- Depositional and deformational sequence

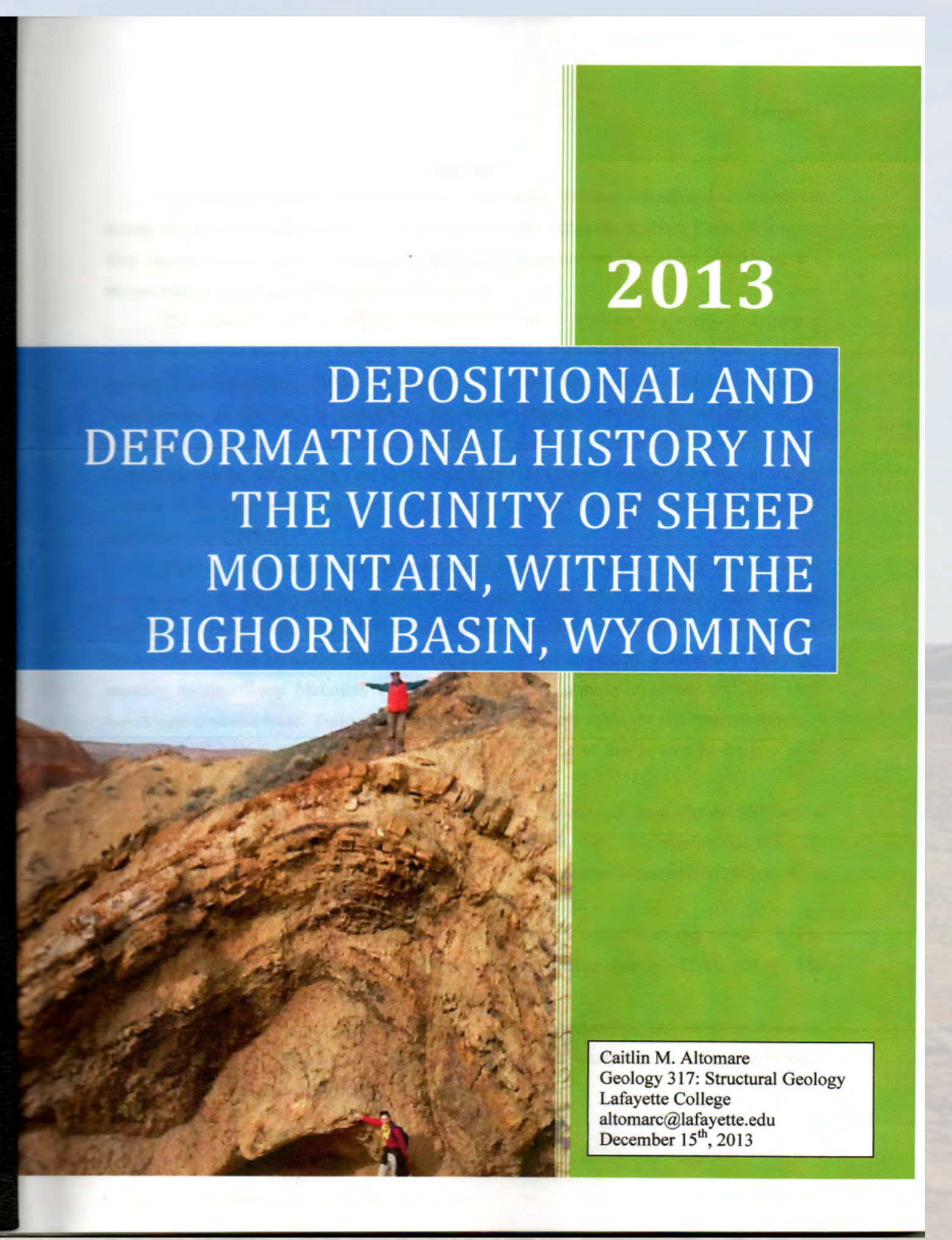




\section{App Development Background \& Rationale}

- Much of geology is a field science, yet interpretation has become very digital.

- Question is how to bridge analog field acquisition (field book and paper maps) with digital acquisition and processing?

- How to effectively use image bases that are widely available

- What benefits might this have?

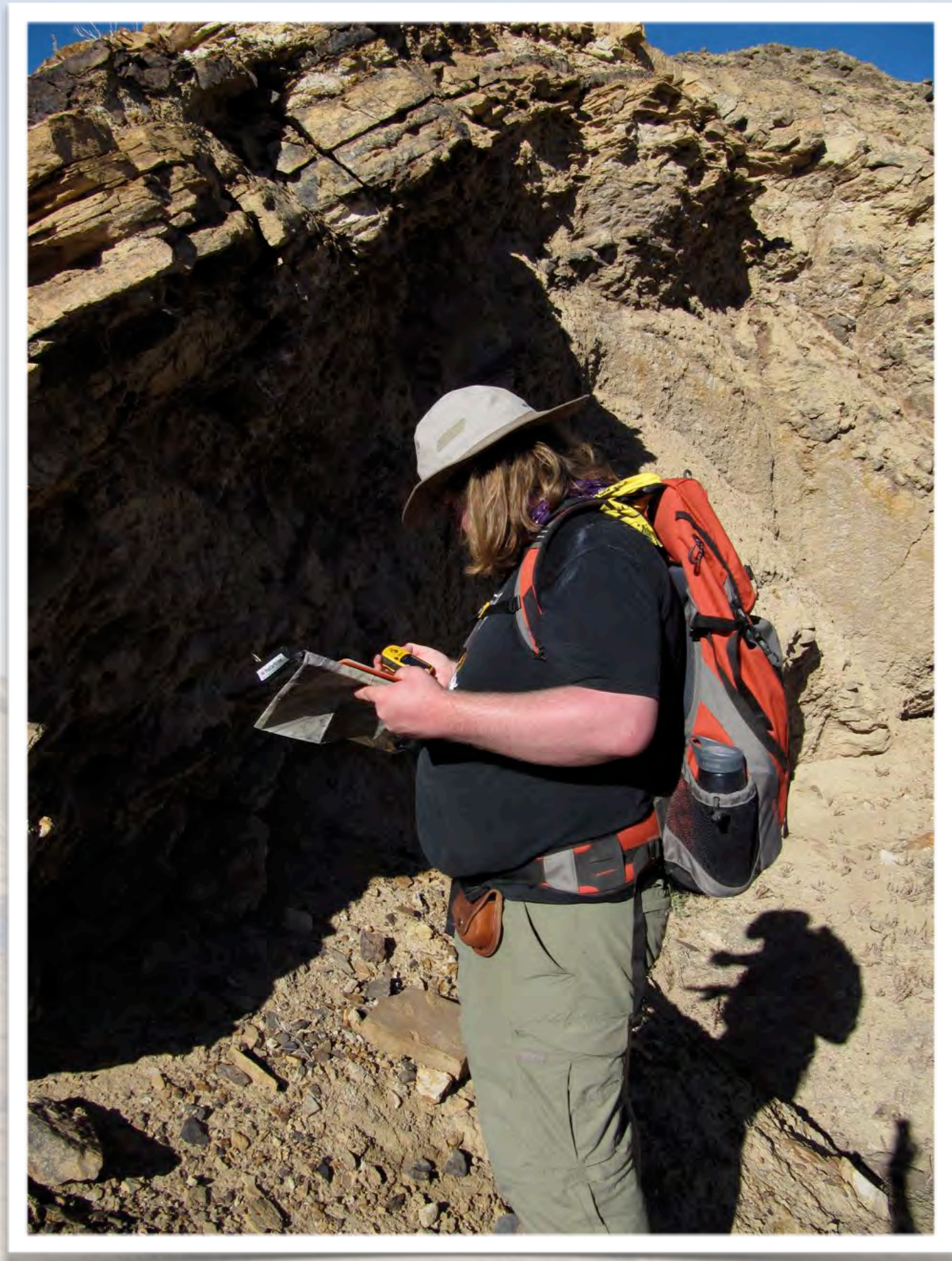




\section{Objectives}

- To develop digital methods for recording field data - Structural: GeoFieldBook

- Sed/Strat: StratLogger

- Use rapidly evolving tablet technology that could mimic, and possibly replace the use of traditional field notebooks.

- Apple iPad

- Record ---> Transcribe ---> Excel ---> Google Earth --->

- Record ---> Map ---> Excel

\section{Geologic map \& Interpretation}
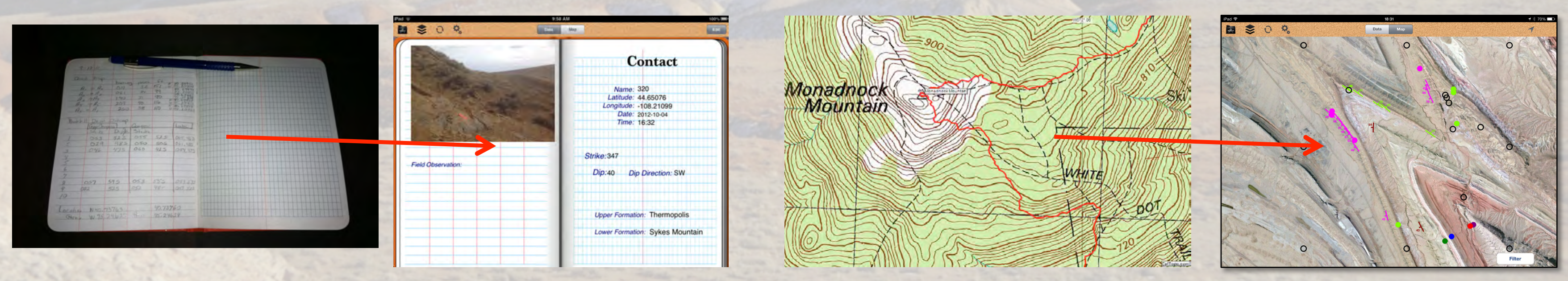


\section{Assumptions}

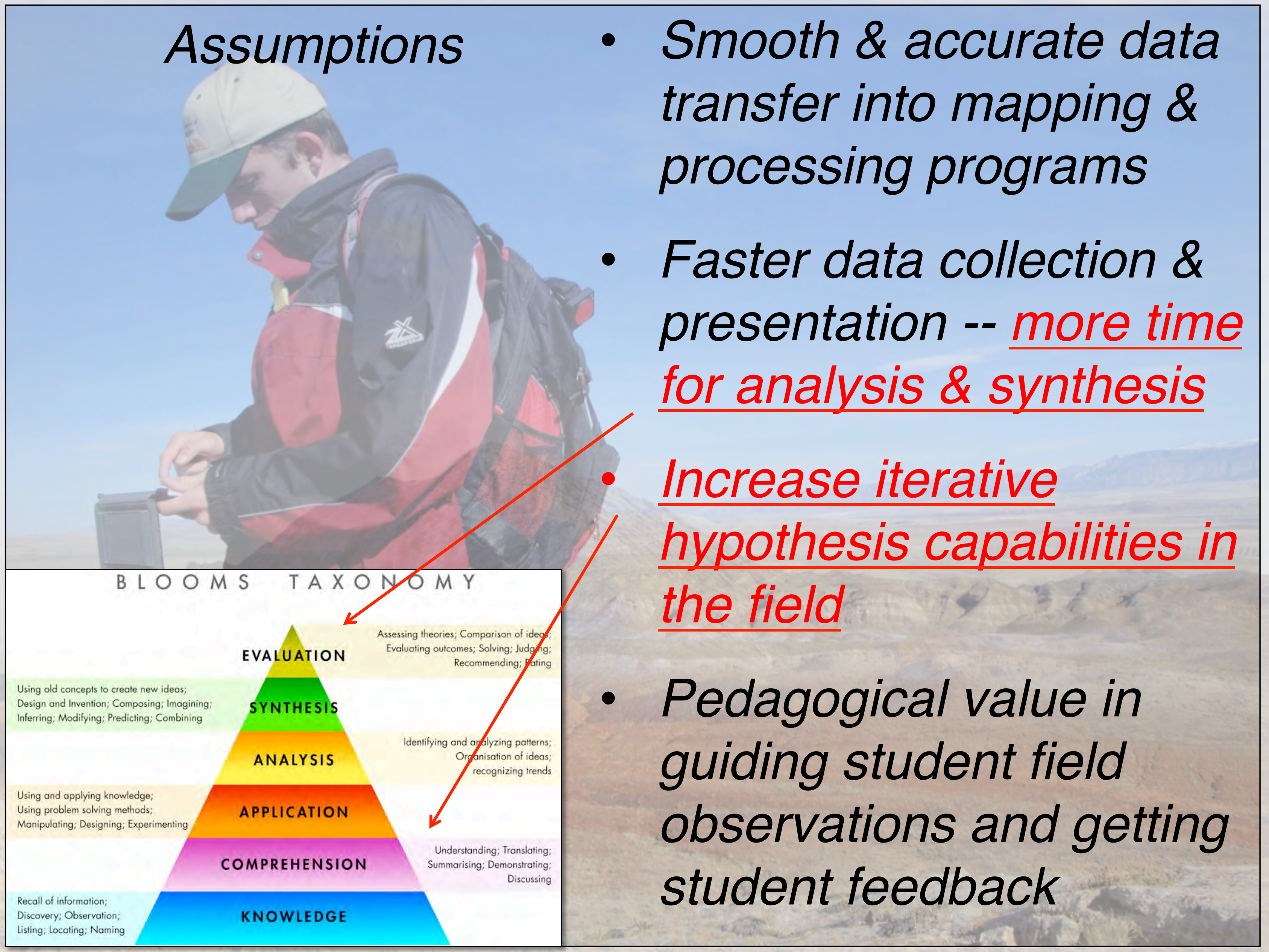




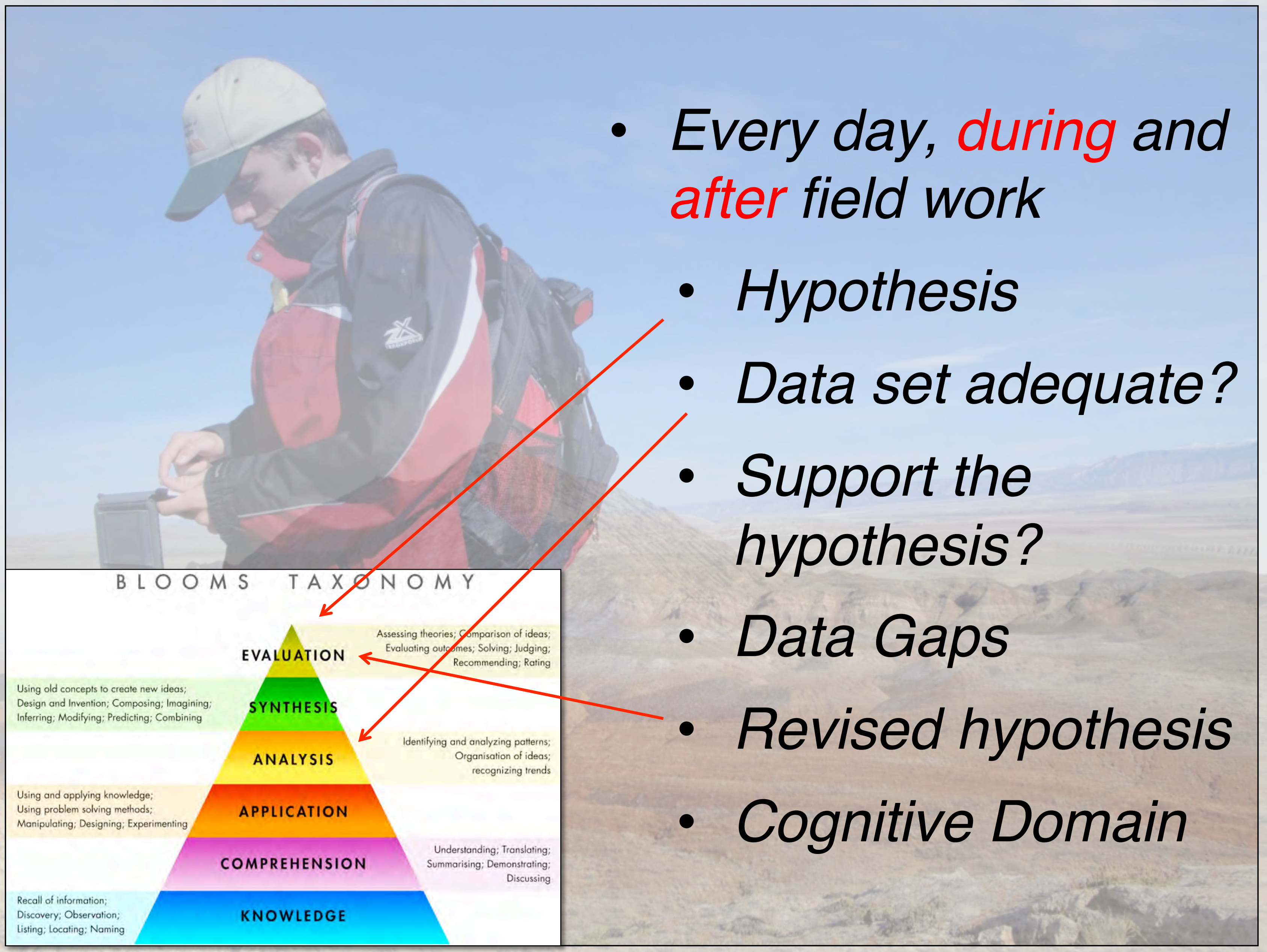




\section{App Development Process}
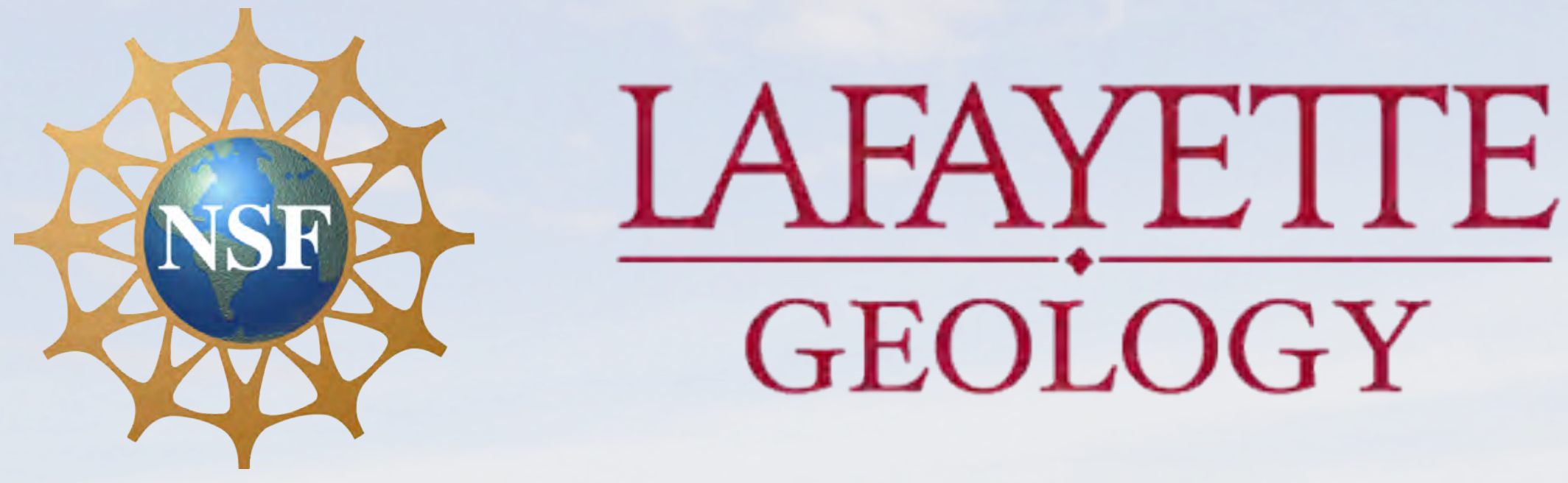

- NSF Computation in the Curriculum project through Prof. Chun-Wai Liew (Lafayette) w/ current support from ITS

- Geology/Computer Science iterative collaboration process - real world experience for CS students

\section{- Programmers}

- Andrew Ho, Kumera Bekele, Kien Hoang, Prabhat Rimal, Carter Tillquest, Lucy McKnight, Franceska Xhakra, Emilie Grybos, Nicholas Escalona, Samuel Courtney, Raymond Machiria, Huy Nguyen, \& Tim Yale 


\section{Common Features: GeoFieldBook \& StratLogger}

- Projects organized in Folders

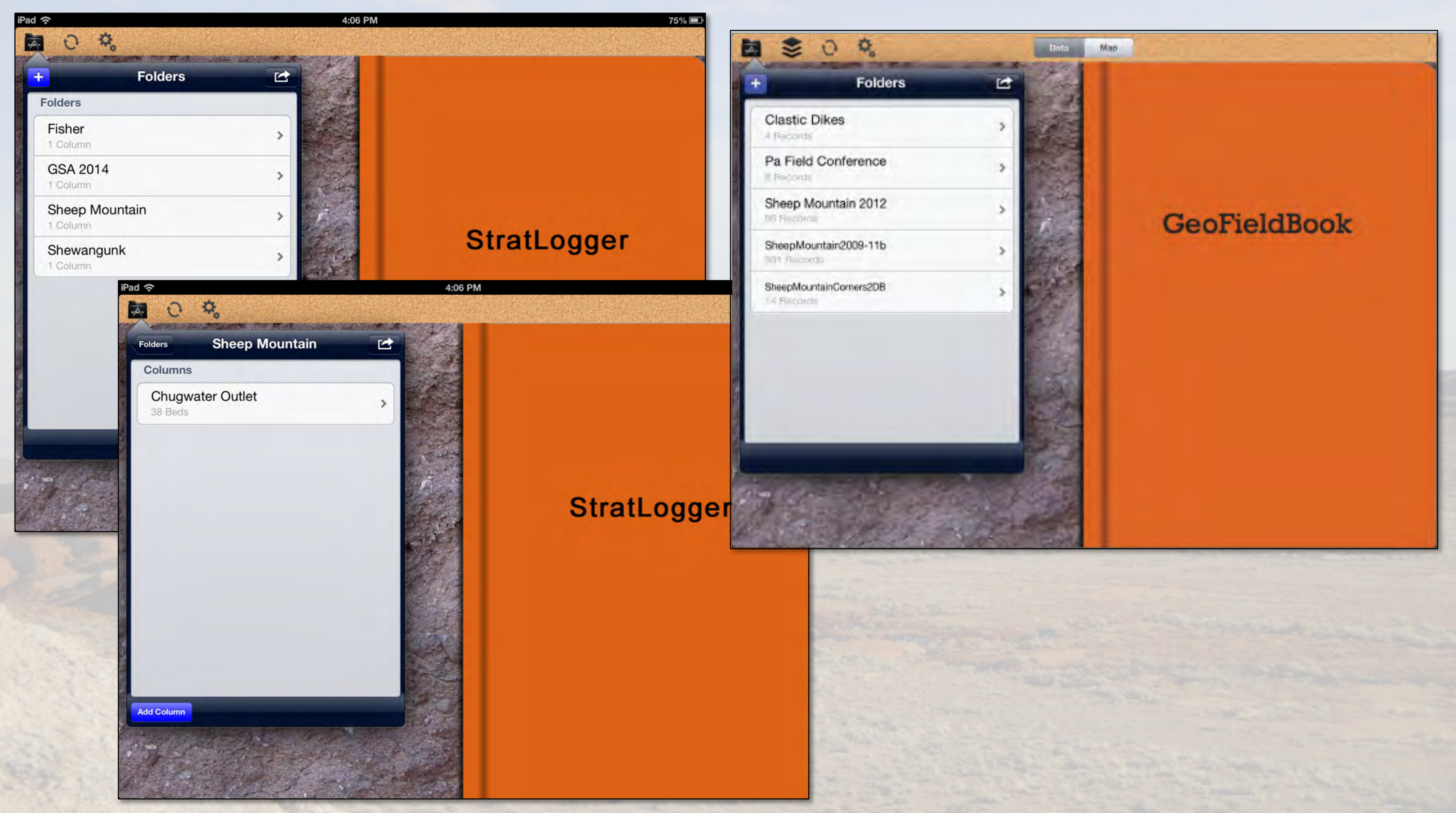




\section{Common Features: GeoFieldBook \& StratLogger}

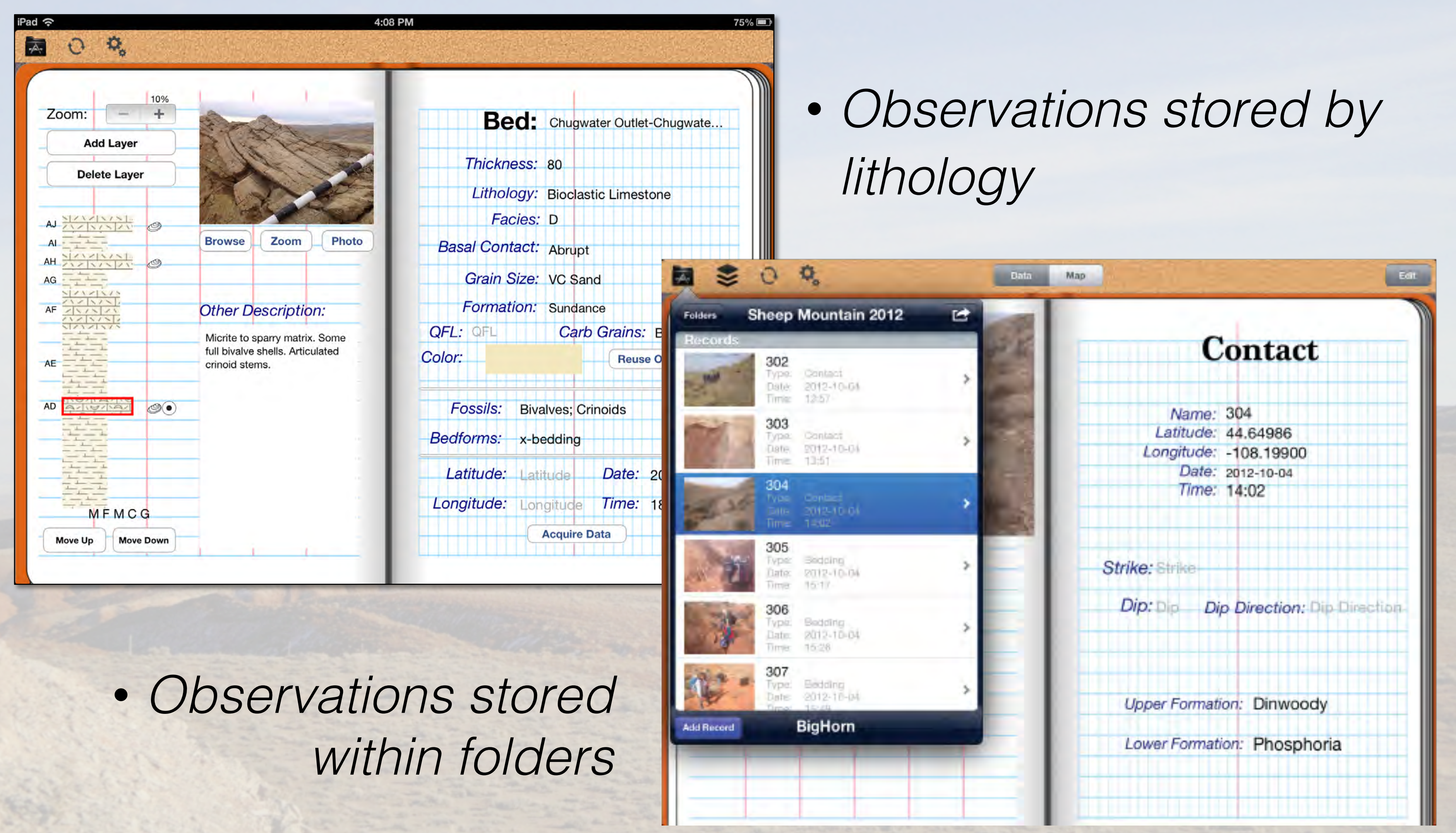




\section{Common Features: GeoFieldBook \& StratLogger}

- Onboard GPS for location and time/date record

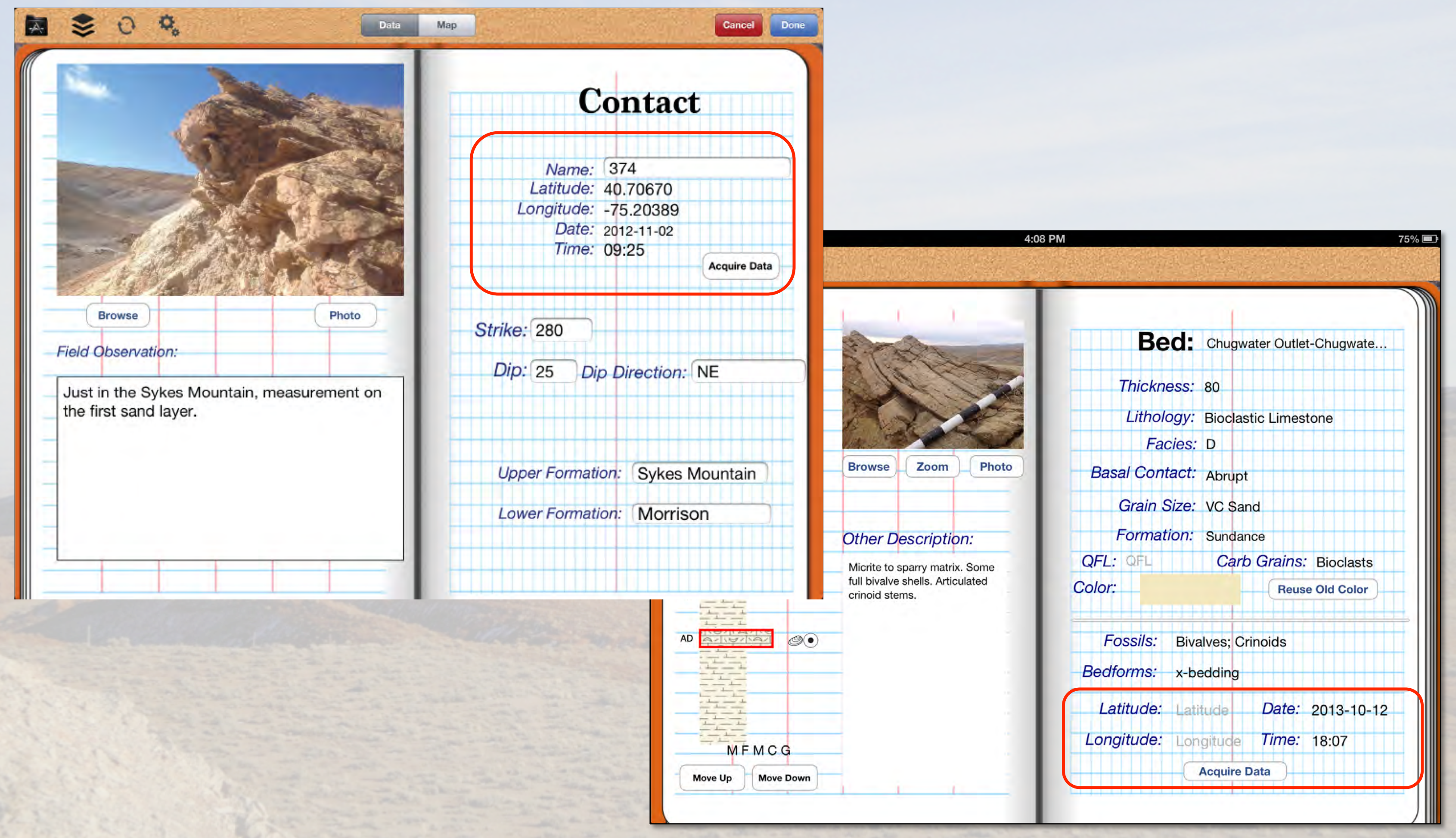




\section{Common Features: GeoFieldBook \& StratLogger}

\section{- Camera}

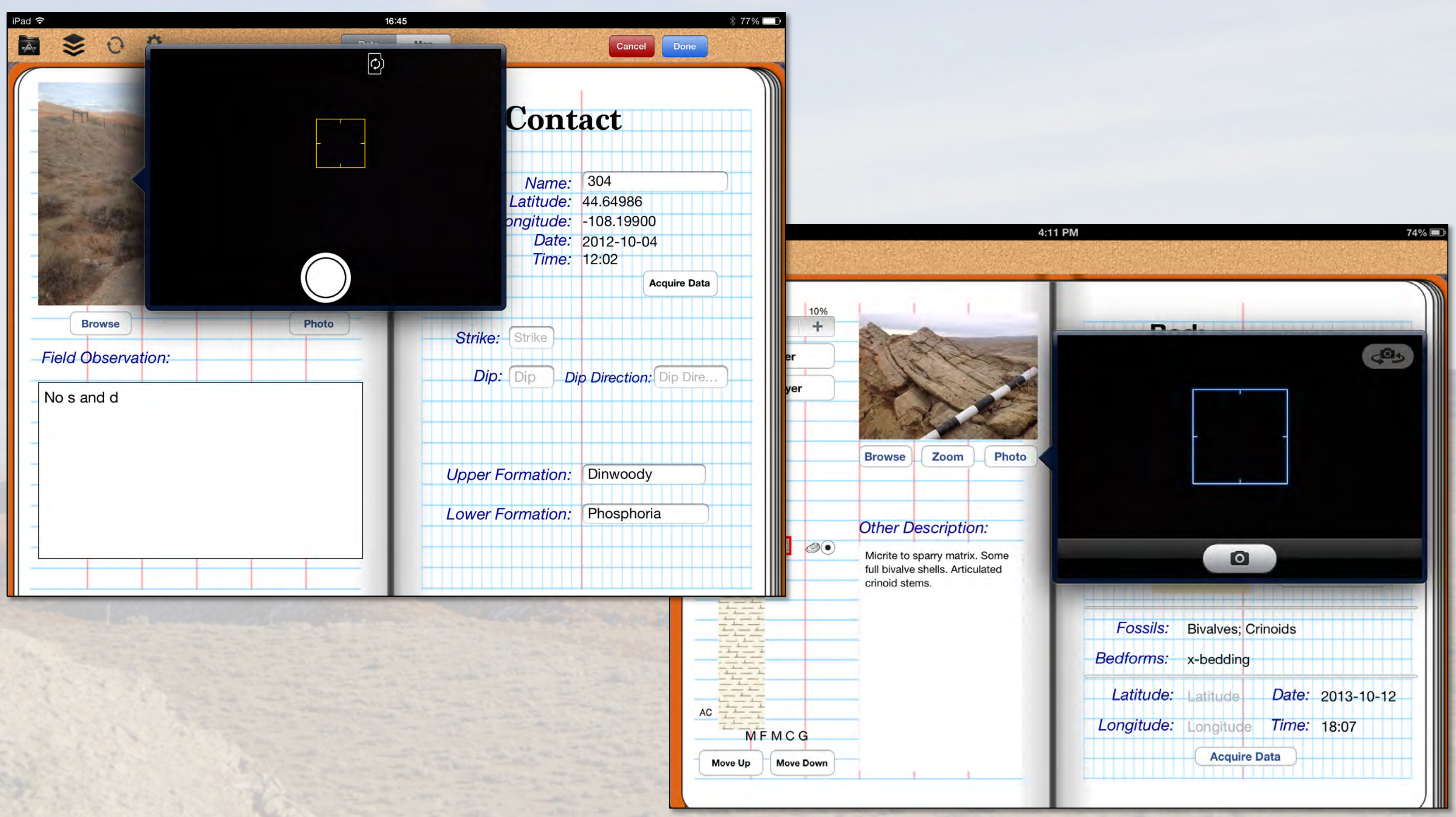




\section{StratLogger}

- Bed-by-bed record for stratigraphic data

- Stratigraphic column built as lithologies are entered

- Fields prompt students to record complete data set

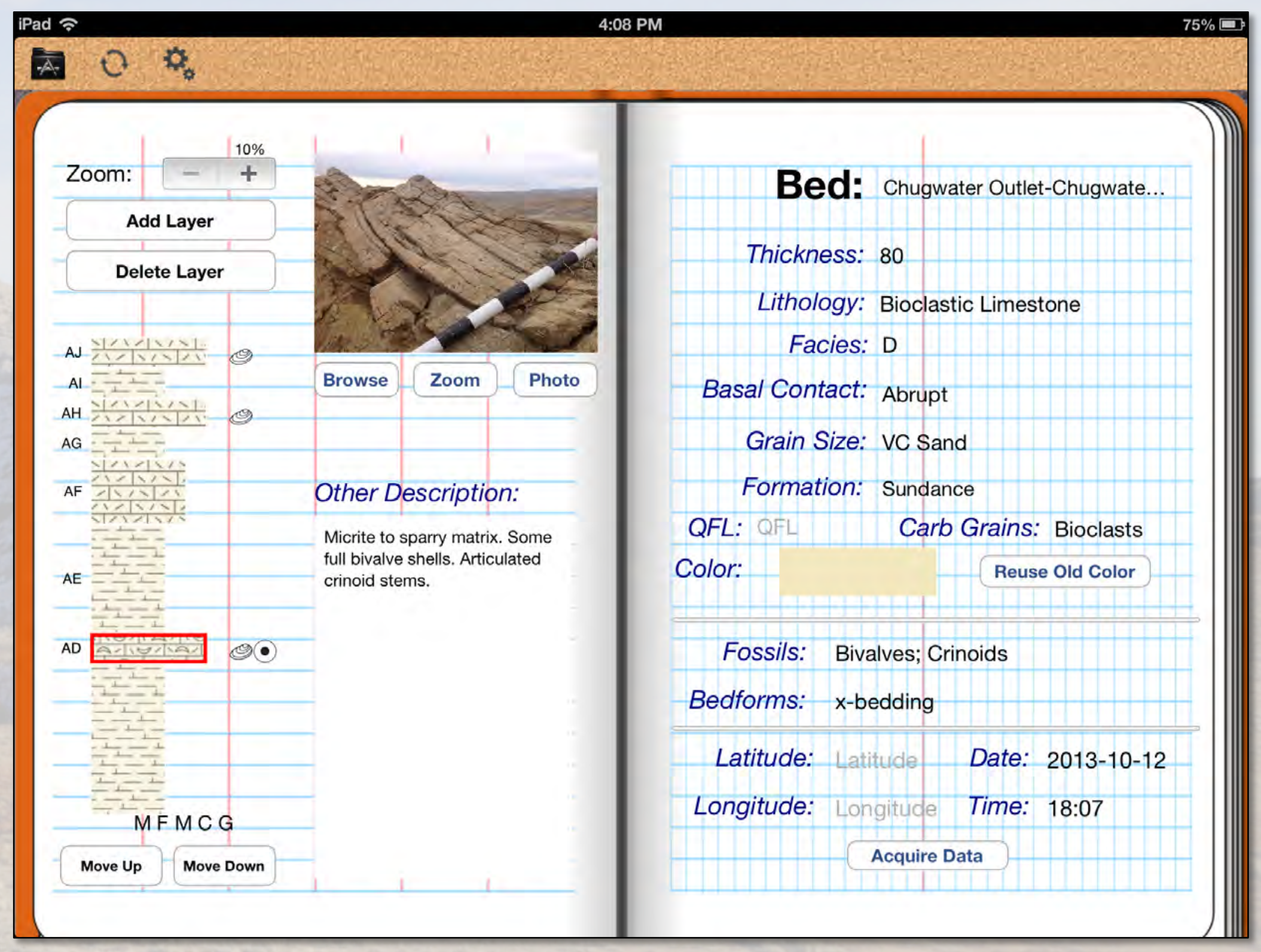




\section{StratLogger}

- Preset but modifiable lists for fields requiring input - Promotes consistency

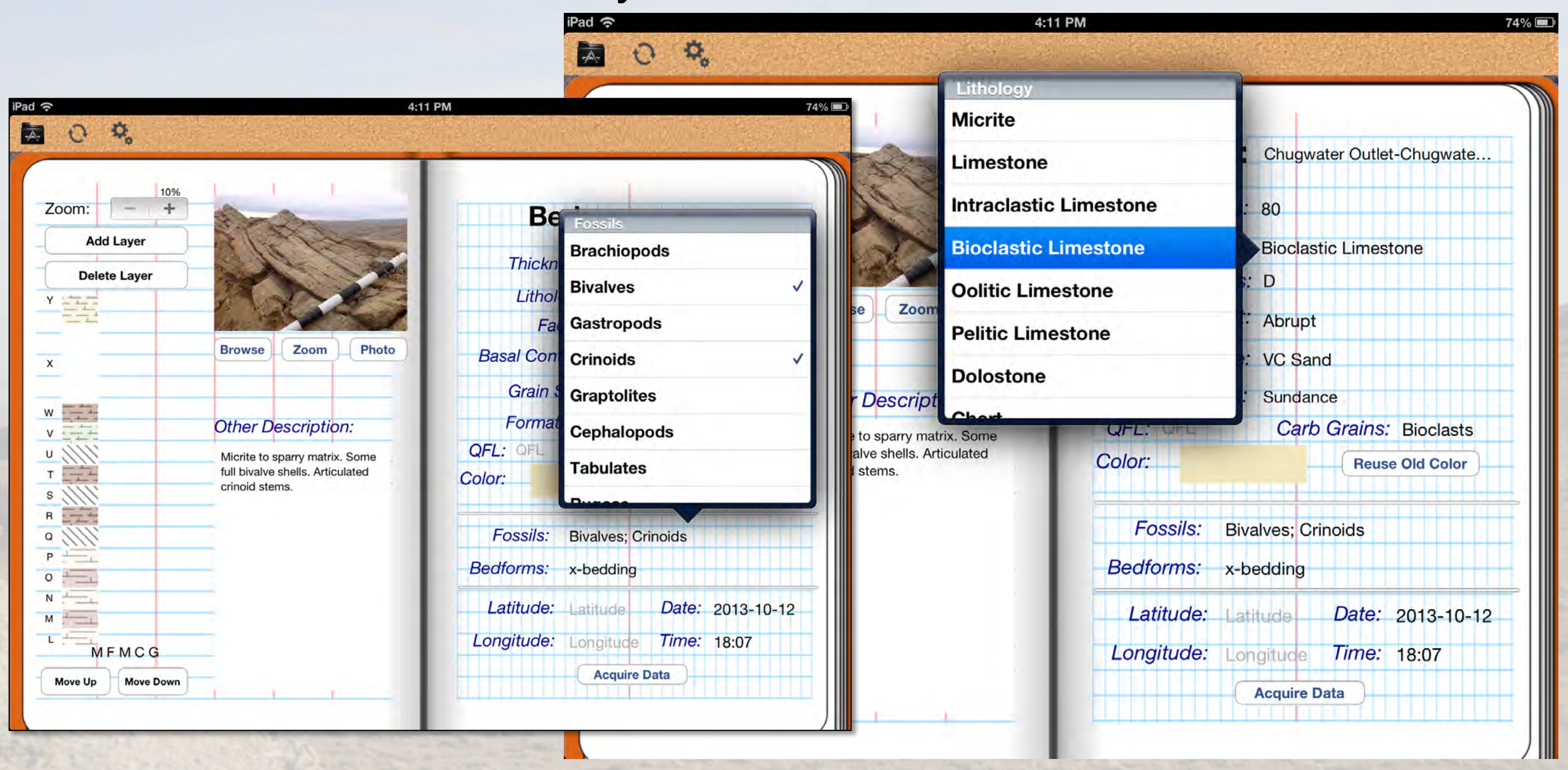




\section{StratLogger}

- Goal is to build a stratigraphic column in the field

- Allows students to:

- hypothesize depositional environments while in the field and

- test interpretations with subsequent observations

- The column can be exported in jpeg format or data can be used to construct column in Illustrator

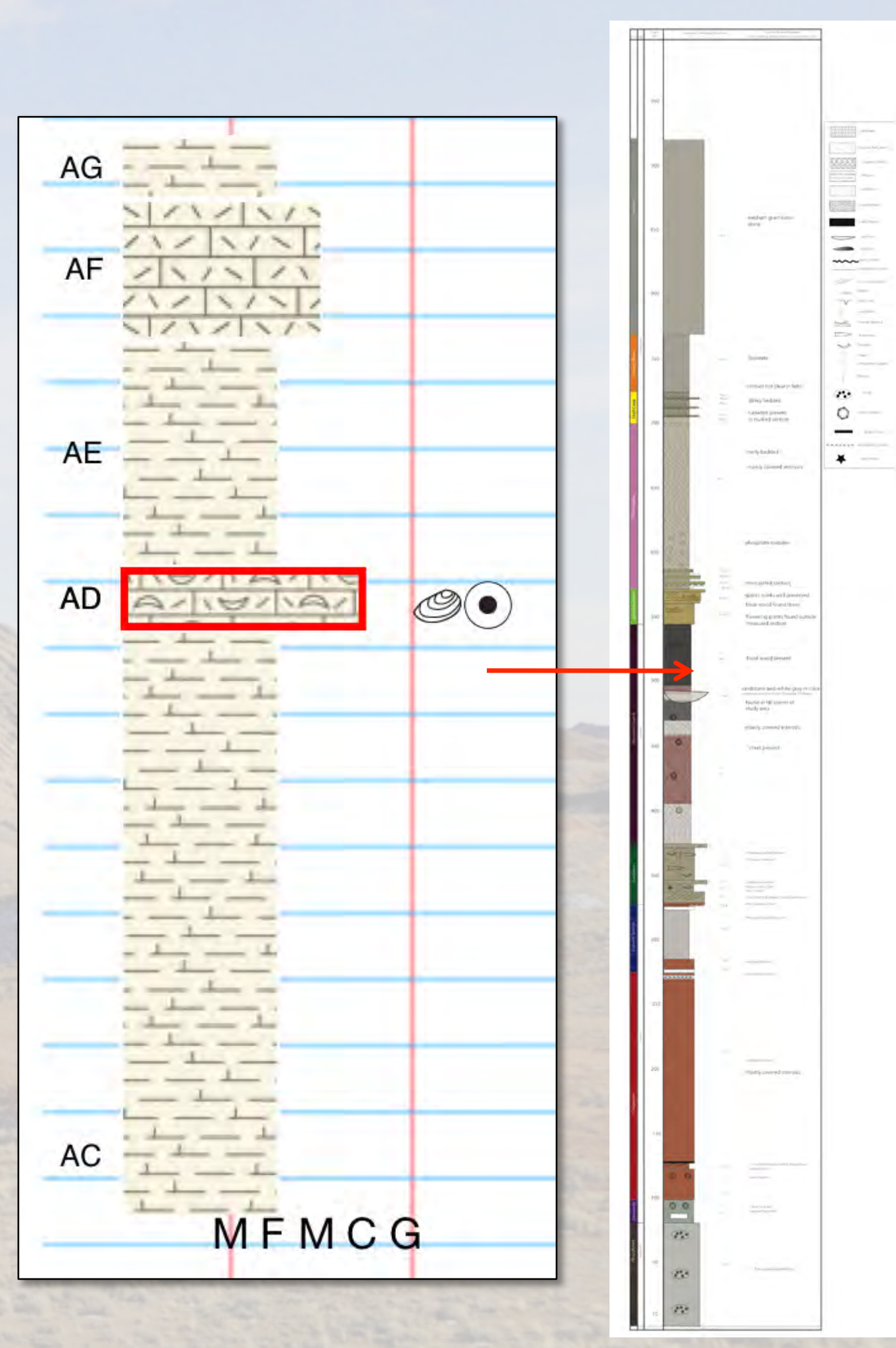




\section{GeoFieldBook}

- Point-based approach for collection and mapping of structural data with the goal of creating a geologic map externally

- Field book replacement with field prompts

- Image base with real-time presentation of oriented data

- Objective is to get students to imagining structural relationships

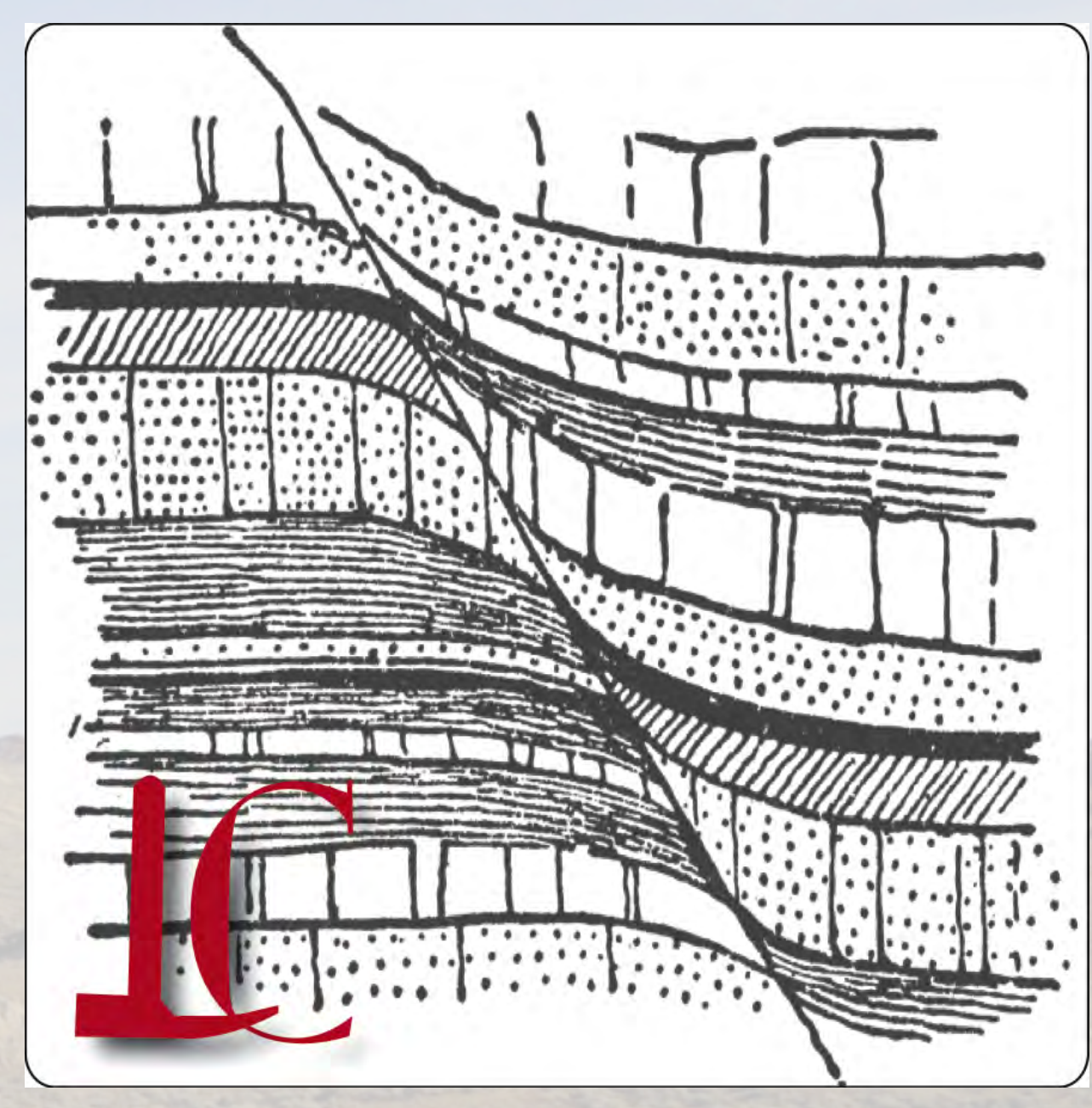
while they are still in the field 


\section{GeoFieldBook}

- Currently select from 4 record types plus "Other" - Also an ability to custom design 5 additional types

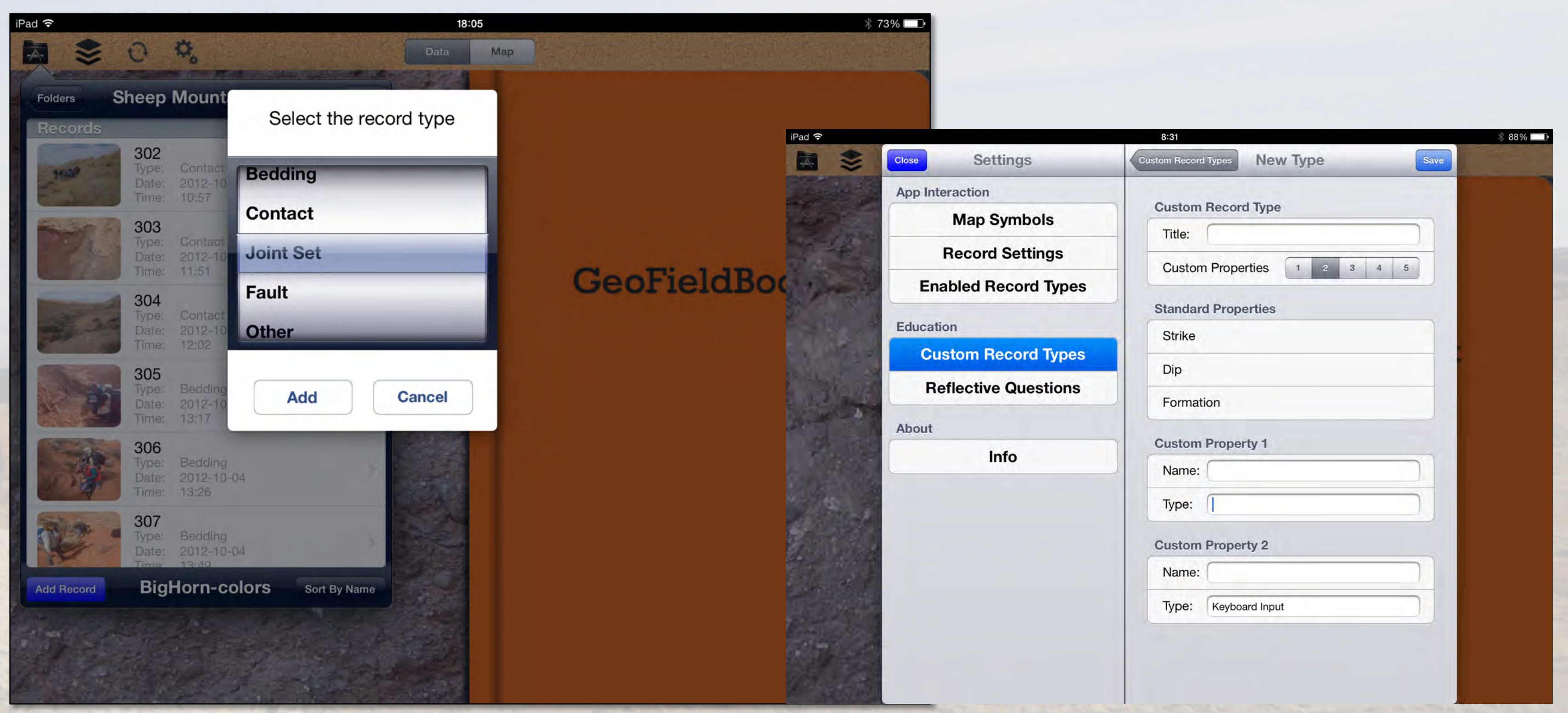




\section{GeoFieldBook}

- Page for each type: prompts for appropriate information

- Especially important for beginning field students

- Like StratLogger, preset but modifiable lists for fields requiring input
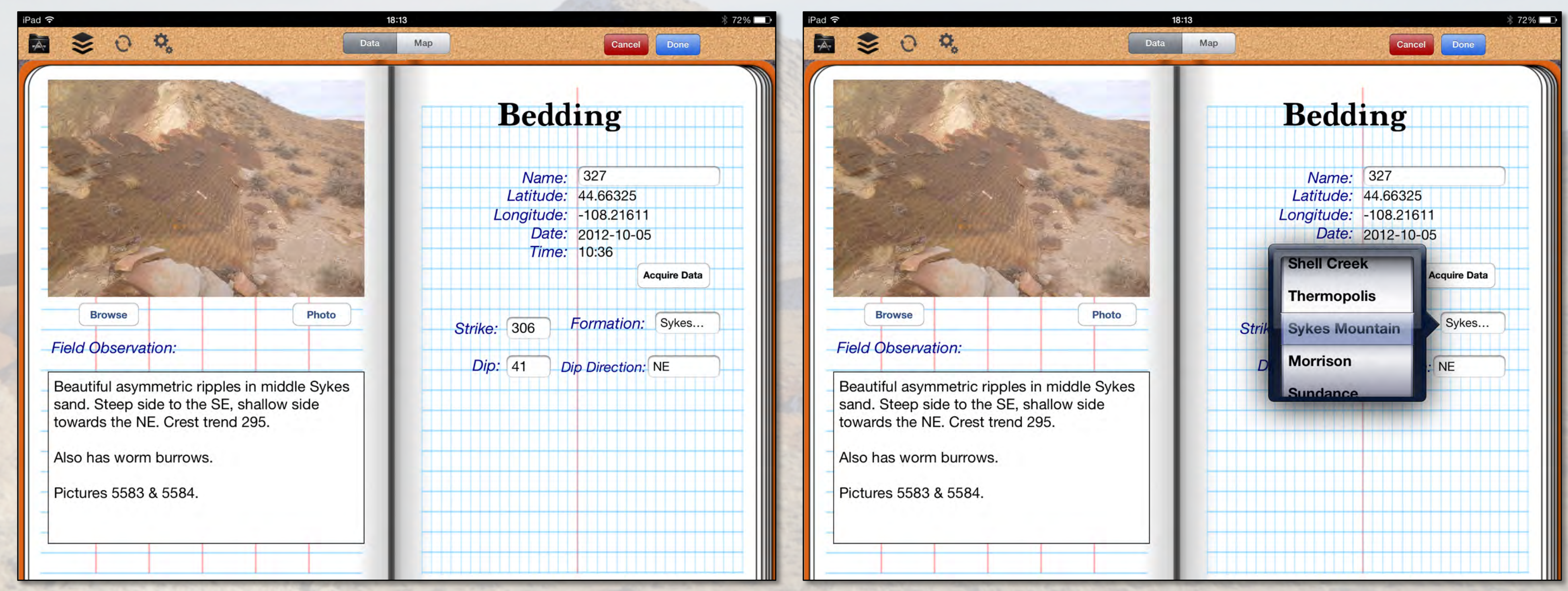


\section{GeoFieldBook}

- Image base is also used as the mapping platform (no paper maps) - gps dot shows current location relative to all collected data... allows for field collection decisions!

- Instant access to previously collected information

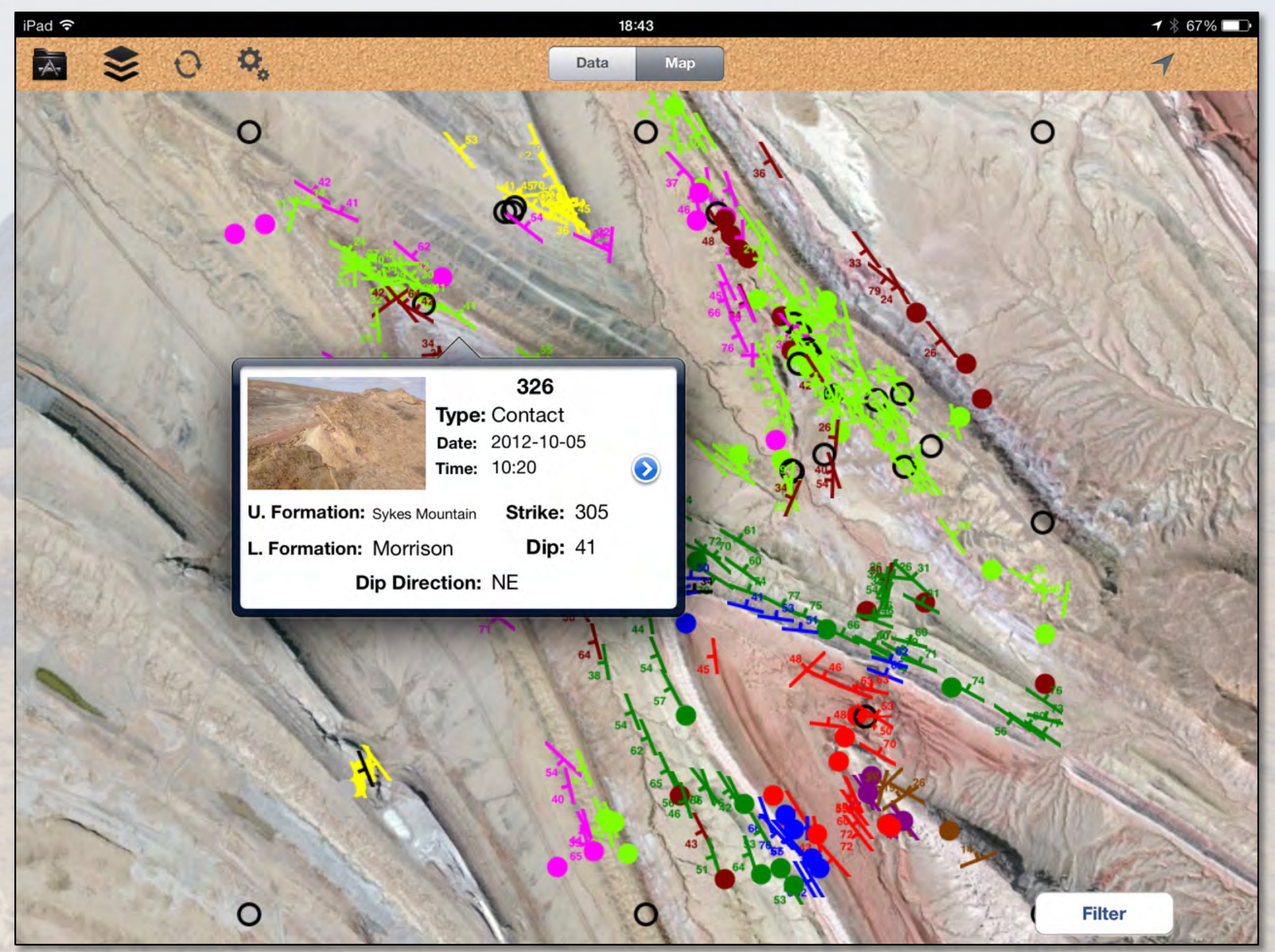




\section{Common Features: GeoFieldBook \& StratLogger}

- Export data files in csv format for use in other analysis or mapping programs (like Google Earth)

- Images are exported with reference within the csv file

- It is also possible to reimport data files and images
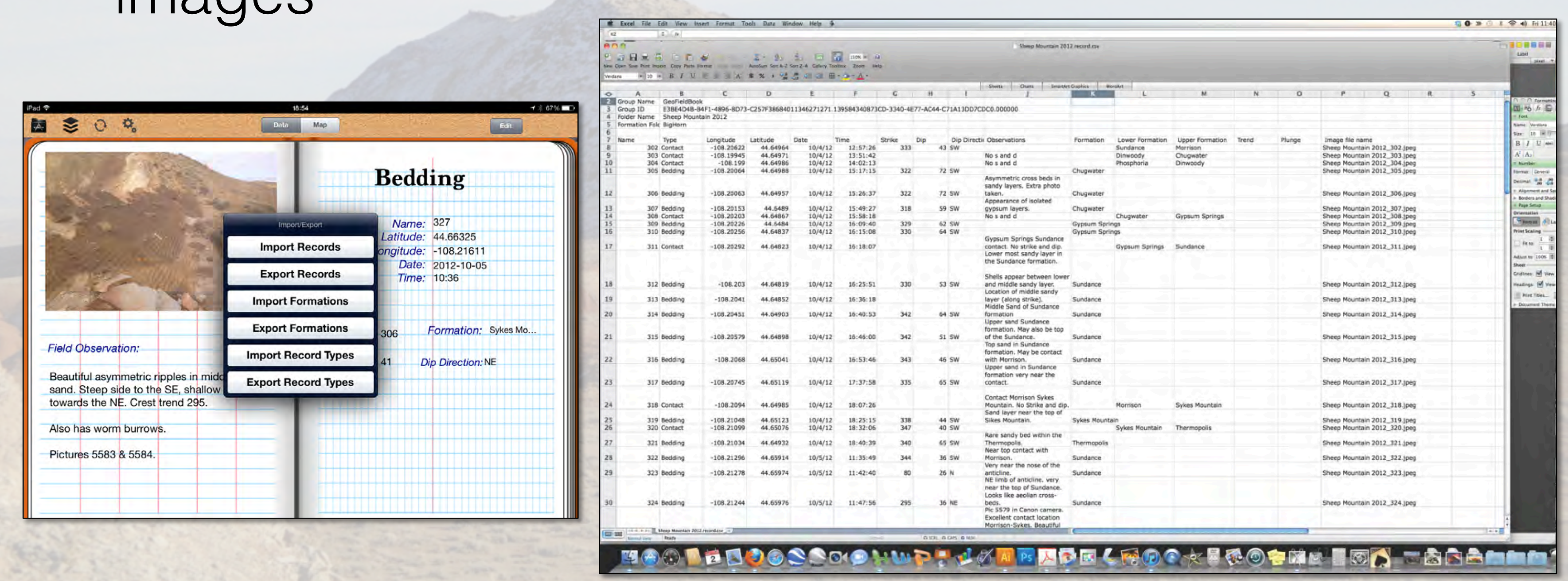


\section{GeoFieldBook \& StratLogger: Digital Efficacy}

- Issue: what is the pedagogical efficacy of these methods

- Reflection Questions - customizable by user (professor)

- We are collecting data on:

- data collection efficiency $\sqrt{ }$

- student learning - field functionality $\sqrt{ }$

- student perception of their learning (?)

- how did this prepare you for future geologizing - post project evaluation (?)
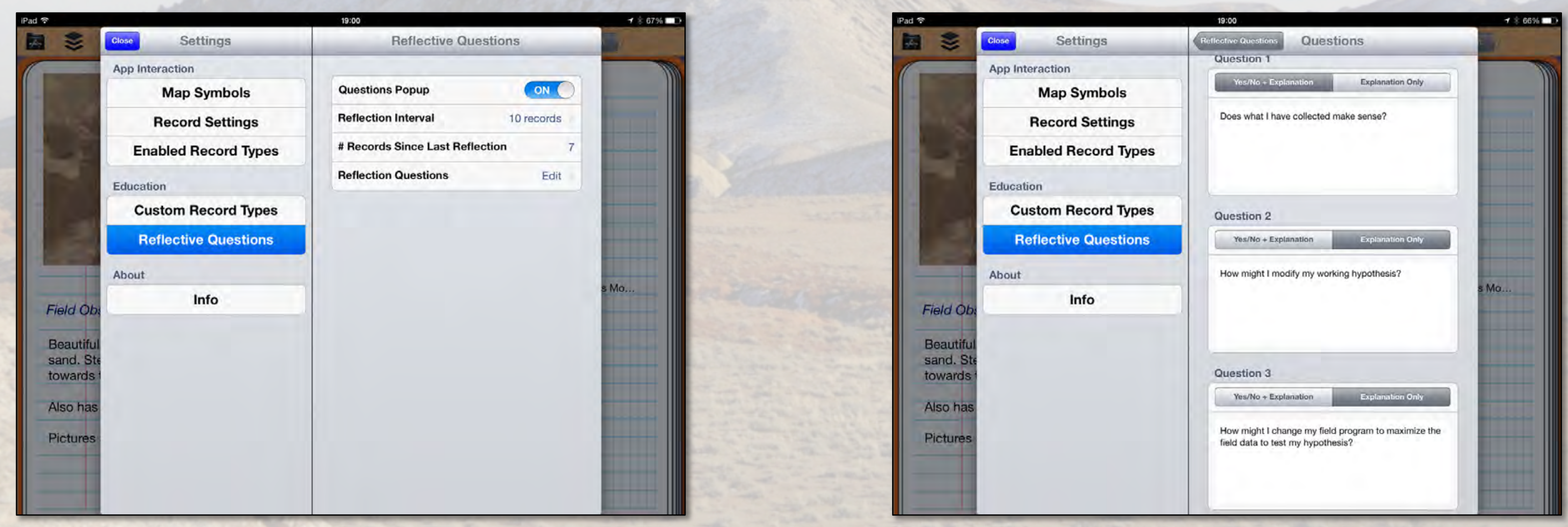


\section{The Ultimate Product}

project

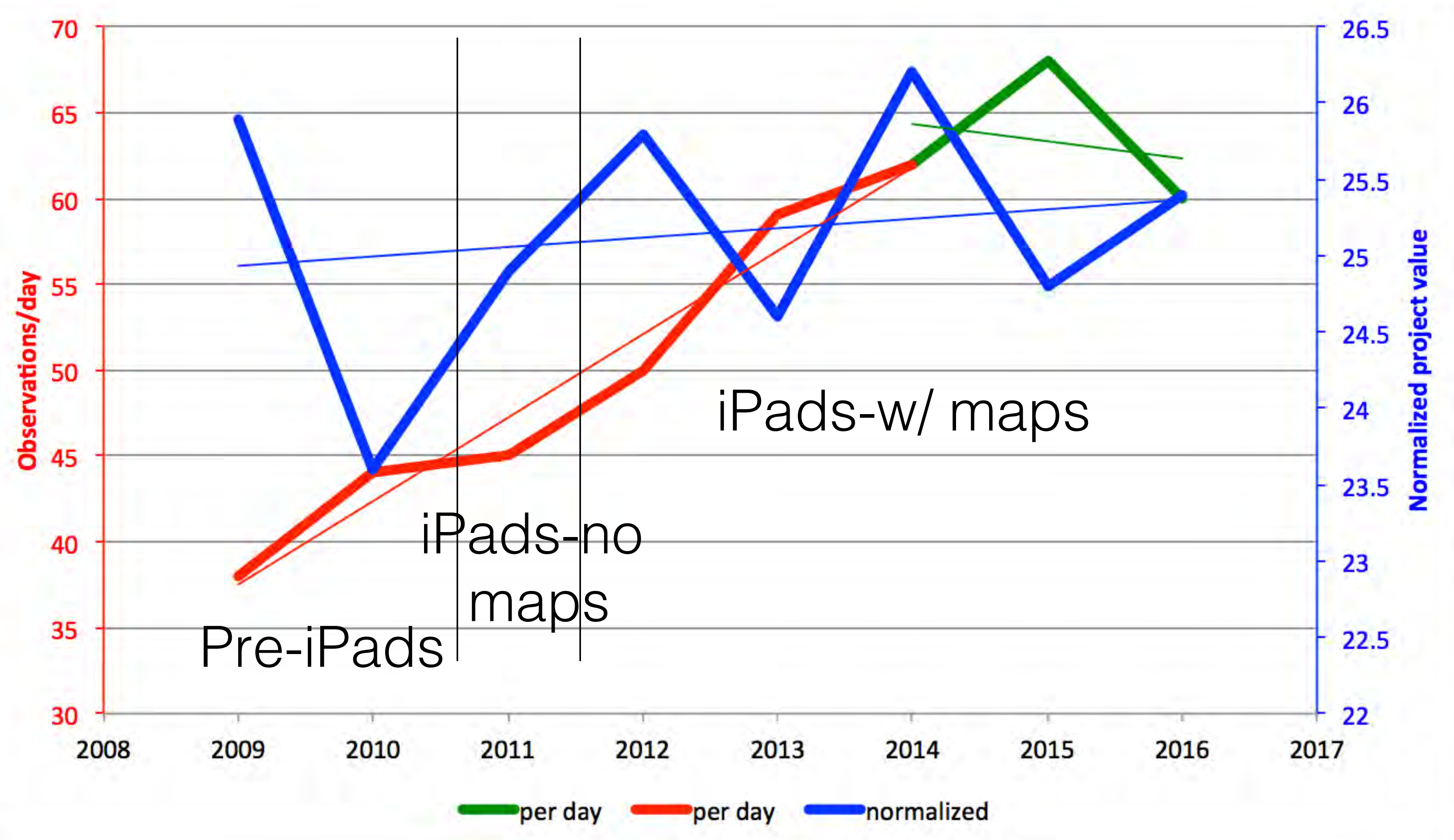




\section{Data to Products}
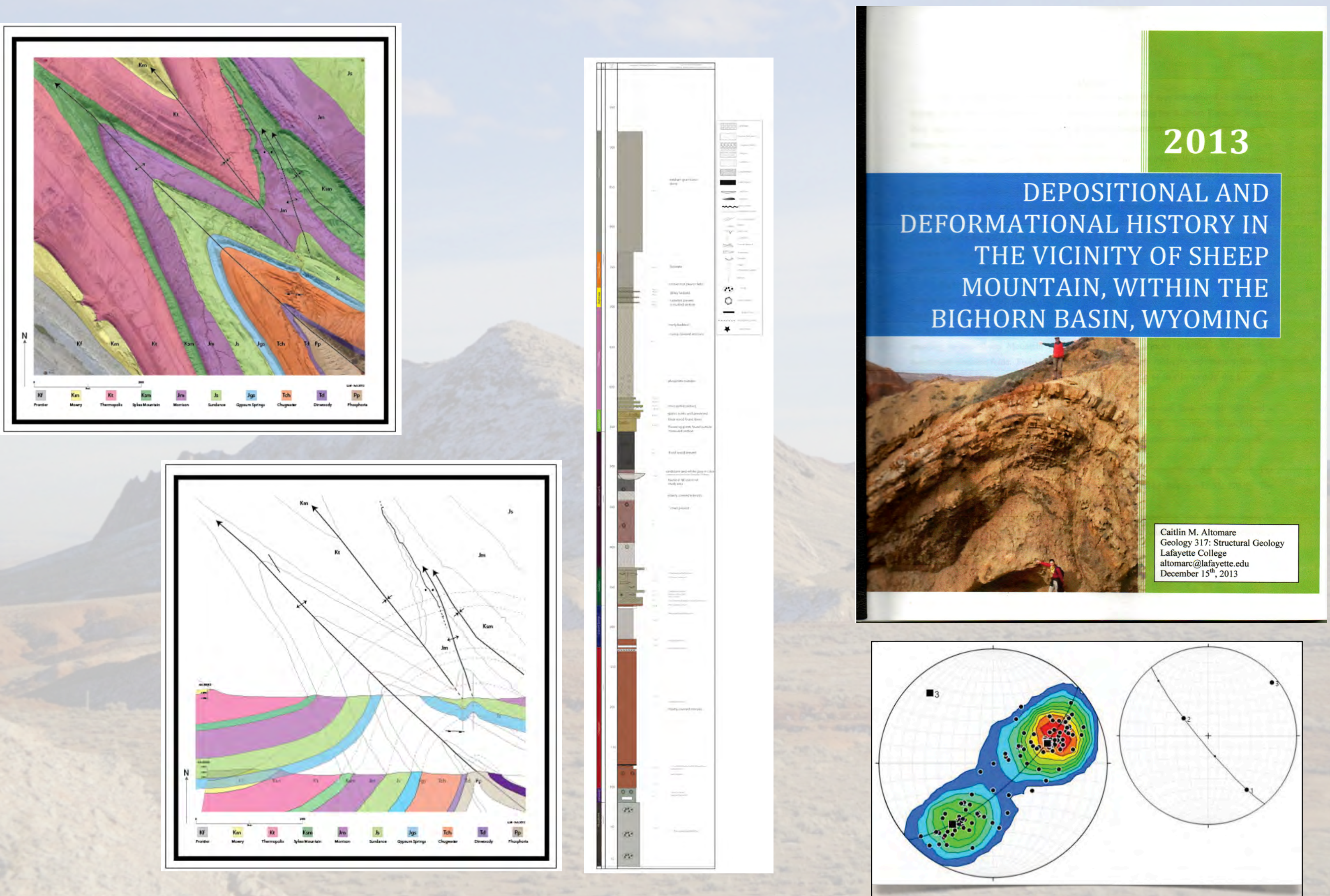


\section{Field Issues and Upgrades}

\section{Anecdotal}

- "I can't imagine not using the collection and mapping App"

- A student from this past fall was required to use paper maps on a large field board for a semester abroad program: "We were 10 time less efficient gathering our data"

- Petroleum professional who also teaches masters students: "...report and maps equivalent to or better than theses I have supervised"

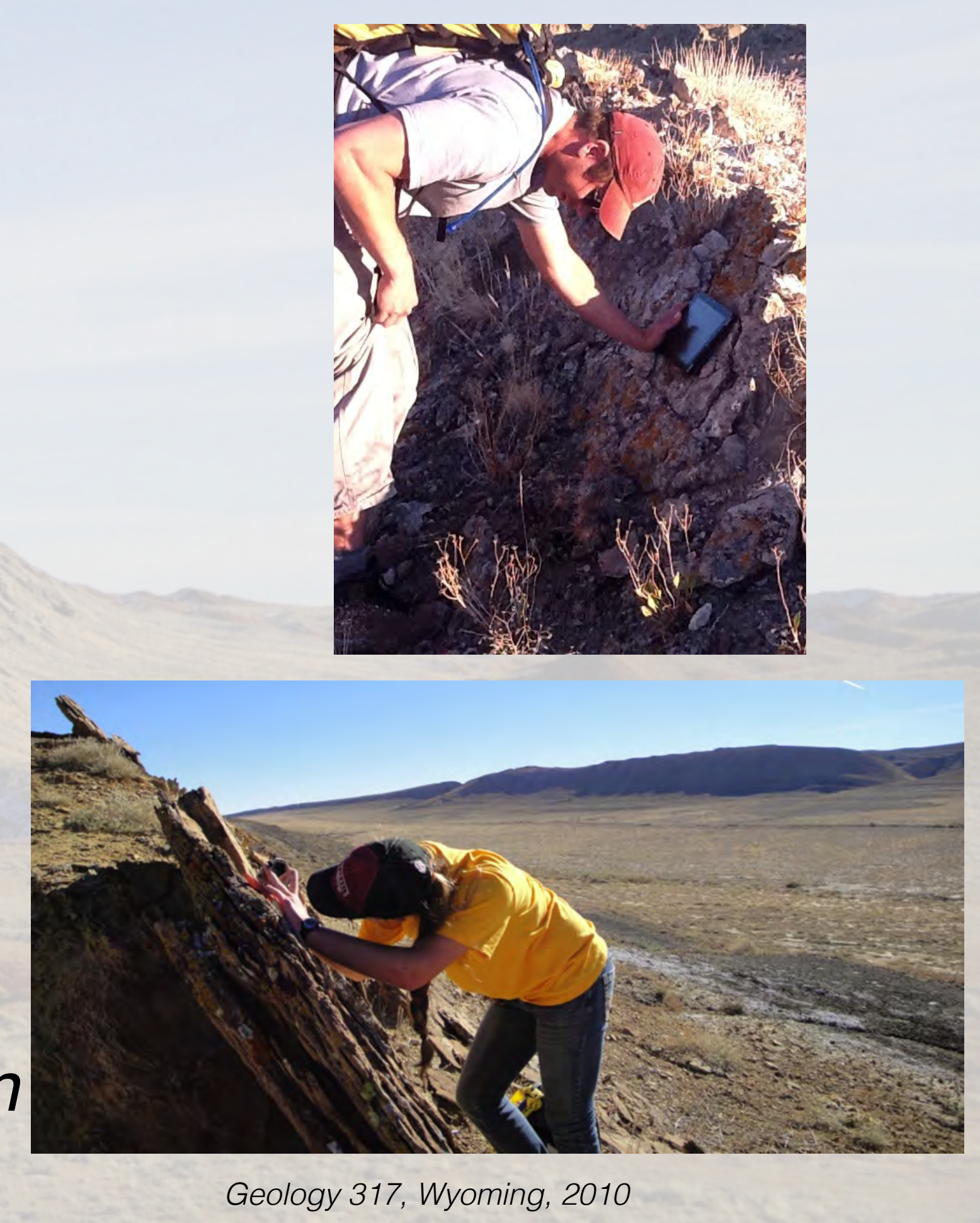




\section{Field Issues and Upgrades}

\section{Questions to be answered}

- Screen visibility in bright sun - adequate

- Durability - covers \& field vests

- Heating up

- Enhancements:

- Real-time cloud backup

- Line drawing?

- Longevity?

- iPad2s - purchased in 2011 - just retired (battery)

- iPad3s - purchased in 2012 - still going strong

- Continued iOS support
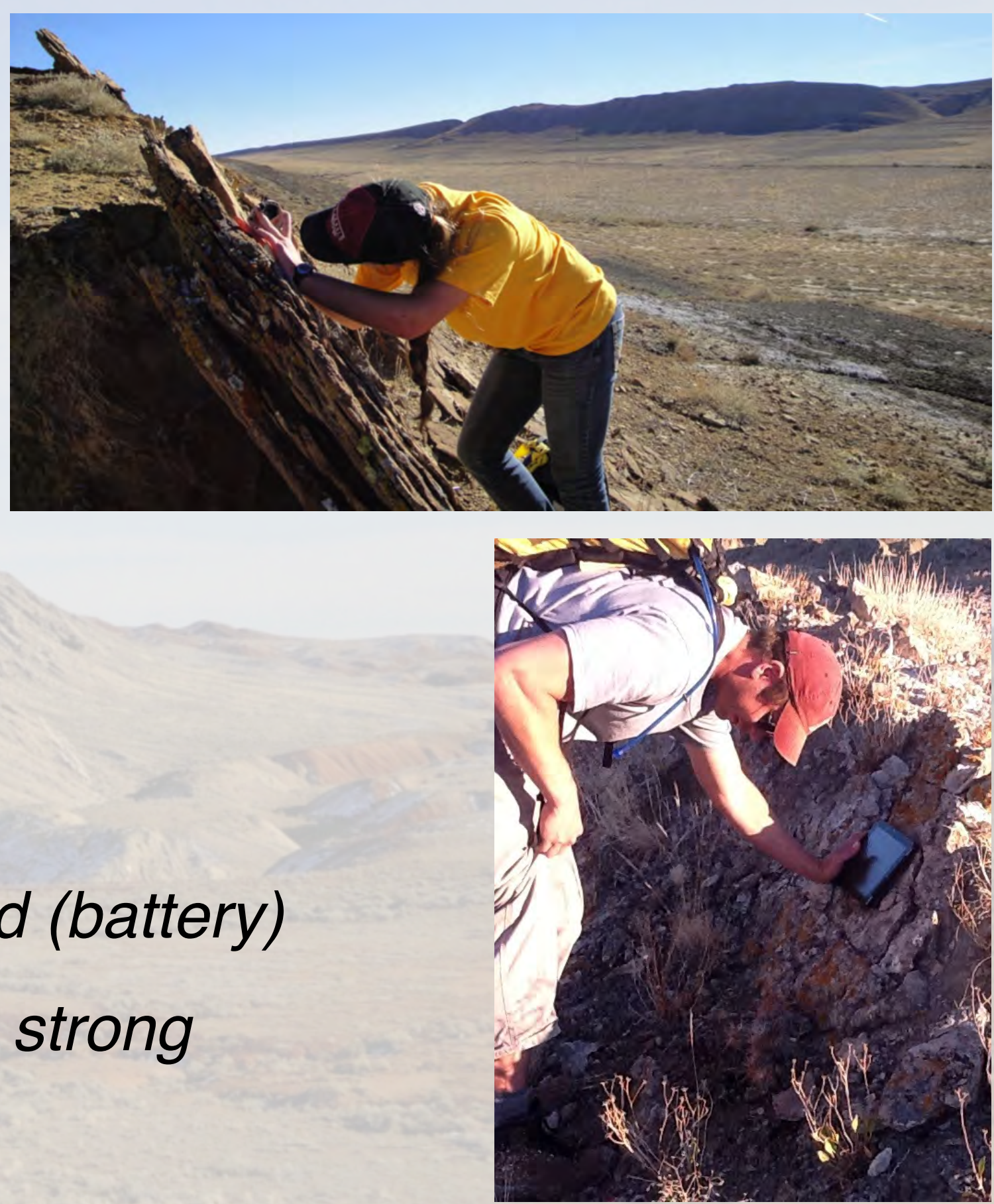


\section{Field Issues and Upgrades}

\section{FAQs}

- How about loss of data?

- "Export" saves a copy of .csv file in different space on the iPad

- Real-time cloud backup coming in next version $\rightarrow$ probably Goolge Drive

- Enhancements:

- Line drawing?

- On maps, images?

- Do we use digital platforms for other applications?

- Image Annotation

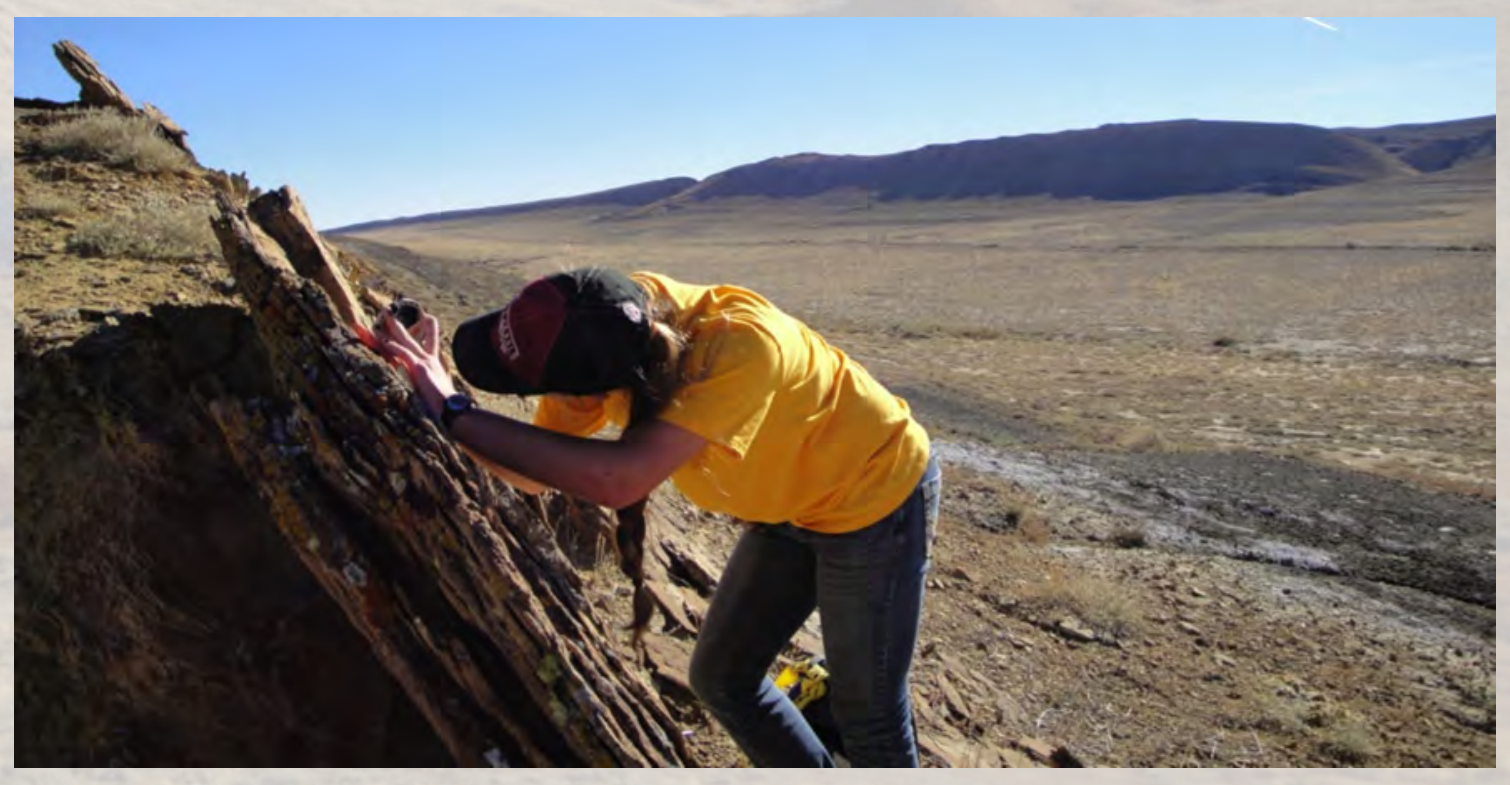




\section{Questions?}

- GeoFieldBook and StratLogger are available for Free at the Apple App Store

- iPads will be available during the break and at the end of the session 


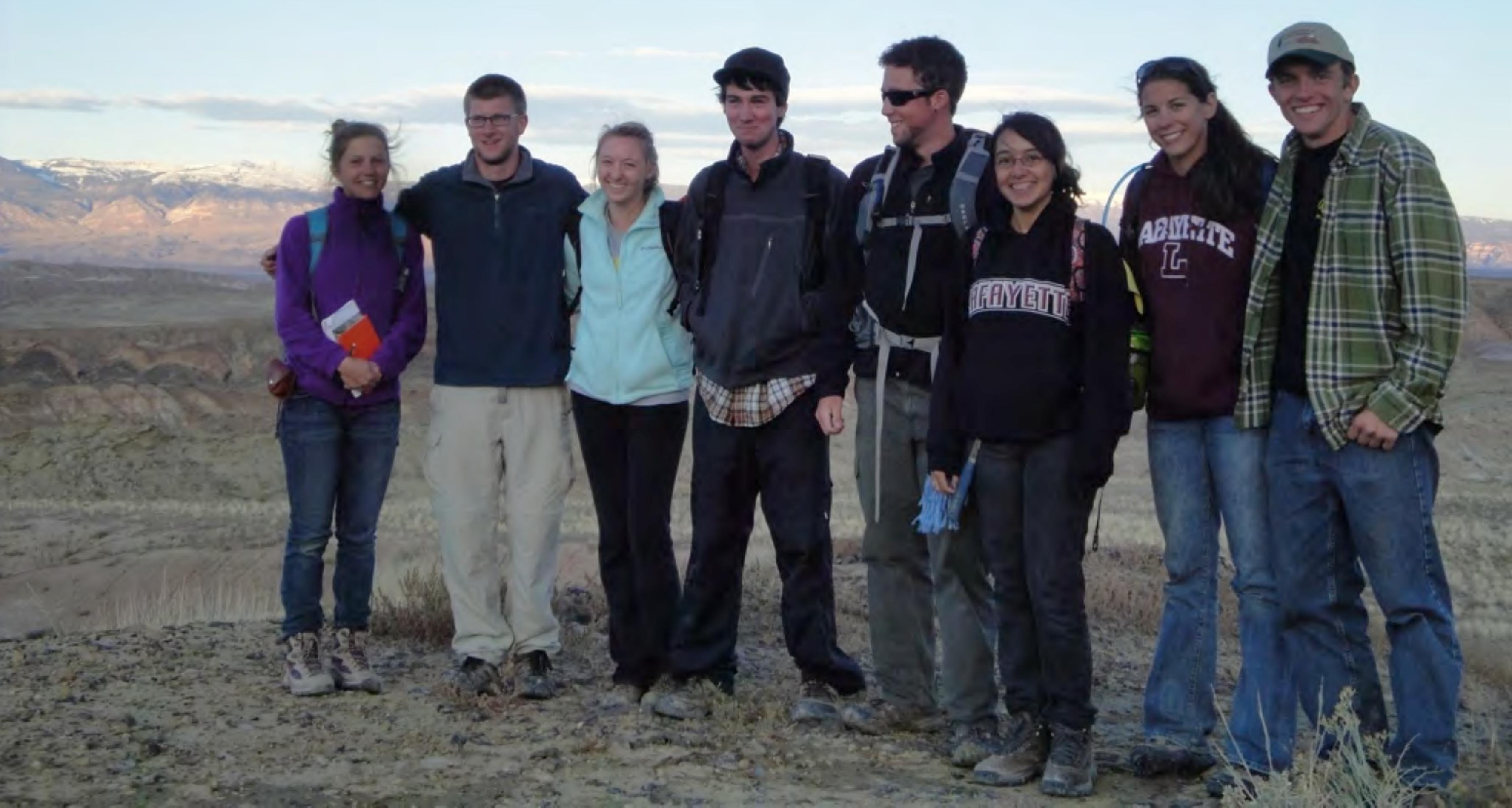




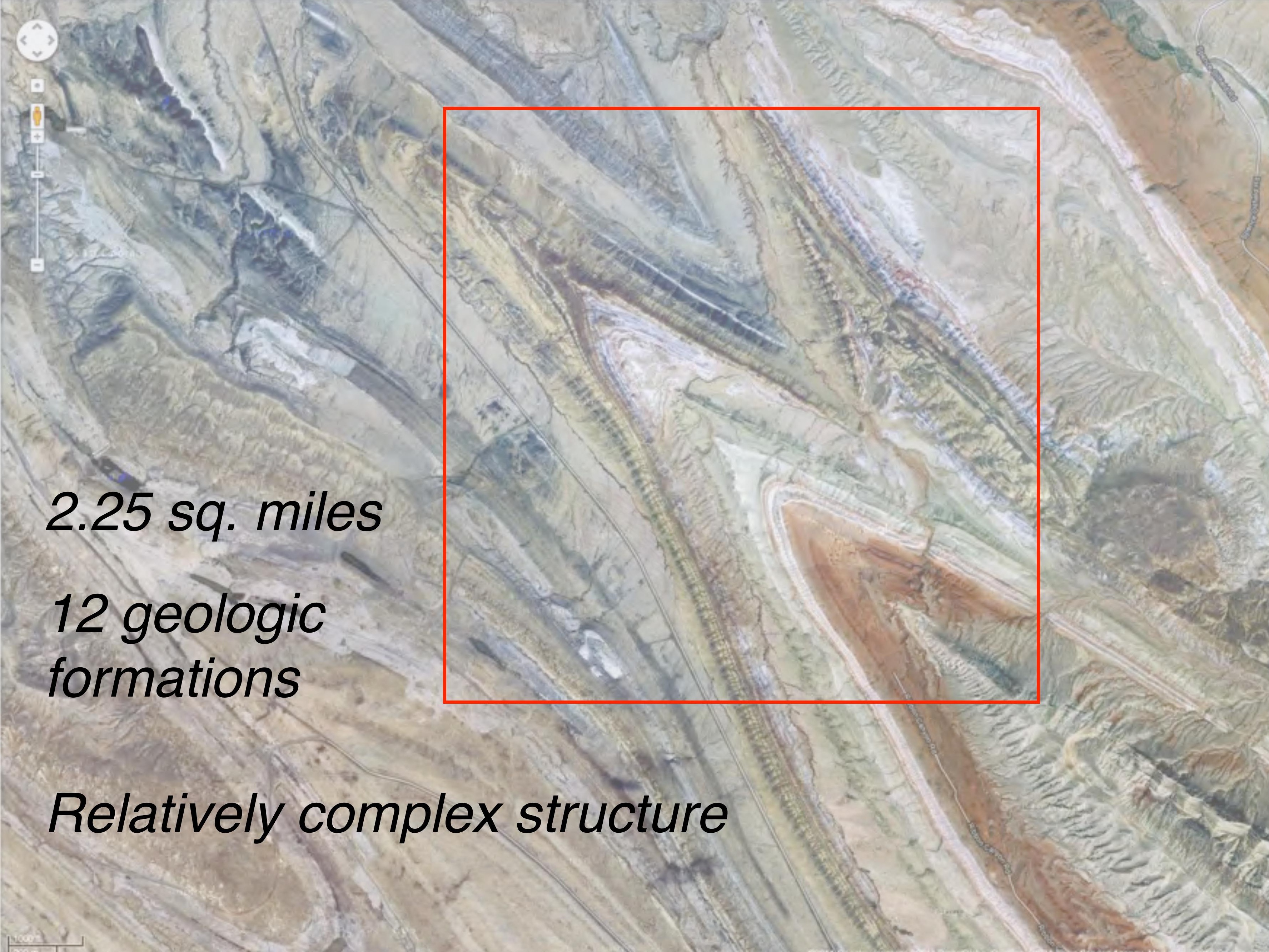




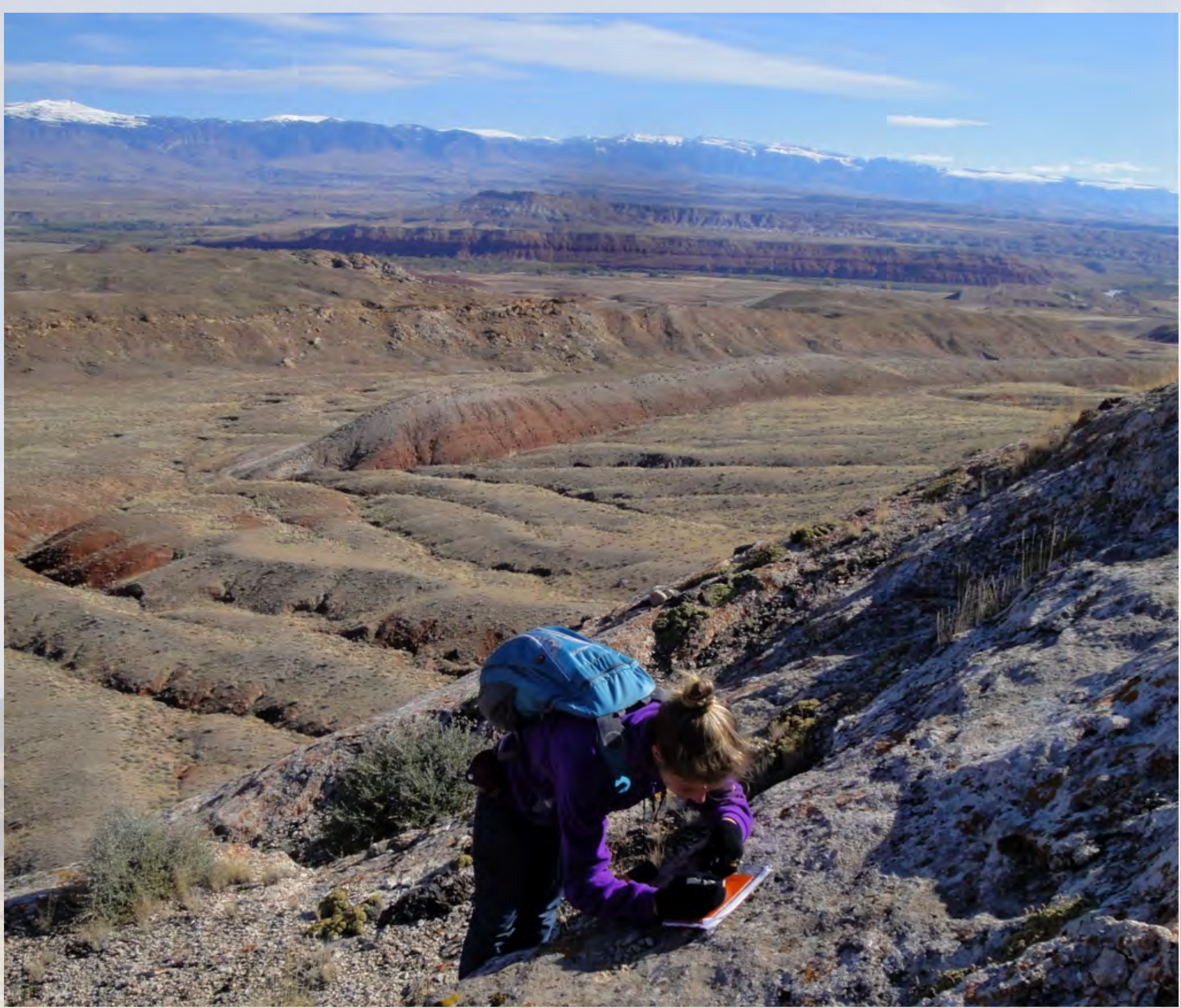

